\title{
DIE SCHIEDSGERICHTLICHE BEILEGUNG VON PRIVATEN INVESTITIONSSTREITIGKEITEN IM LICHTE DER WELTBANKKONVENTION VOM 18. MÄRZ 1965
}

\author{
Von Peter Fischer
}

\section{Einführung}

Am 18. März 1965 wurde vom Direktorium der Internationalen Bank für Wiederaufbau und Entwicklung (im folgenden „Weltbank") den Mitgliedstaaten dieser Organisation der Entwurf einer „Konvention zur Beilegung von Investitionsstreitigkeiten zwischen Staaten und Angehörigen anderer Staaten"1 zur Unterzeichnung vorgelegt. Dieses im Rahmen der Weltbank ausgearbeitete Vertragswerk, das mit 14. Oktober 1966 in Kraft getreten ist, verdient insbesondere aus folgenden zwei Gründen Beachtung:

Zum ersten schafft es die institutionellen Grundlagen für die Beilegung von solchen Streitigkeiten, die zwischen kapitalimportierenden Staaten und ausländischen Investoren über die in jenen Staaten getätigten Kapitalanlagen² häufig auf-

1 Hierzu siehe insbesondere: Mario Amadio, Le Contentieux International de l'Investissement Privé et la Convention de la Banque Mondiale du 18 Mars 1965, Paris 1967, 275 S.; Rolf Berger, Internationale Zentrale zur Beilegung von Investitionsstreitigkeiten, Außenwirtschaftsdienst des Betriebs-Beraters vom 15./30. Dezember 1965, S. 434-444; A Broches, Development of International Law by the International Bank for Reconstruction and Development, in: 59 Proceedings of the American Society of International Law, S. 33-38 (1965); ders., The Convention on the Settlement of Investment Disputes: Some Observations on Jurisdiction, in: 5 Columbia Journal of Transnational Law, No. 2, S. 263-280 (1966); ders., The Convention on the Settlement of Investment Disputes between States and Nationals of Other States: Applicable Law and Default Procedure, in: International Arbitration: Liber Amicorum for Martin Domke, The Hague 1967, S. 12-22; George Delaume, La Convention pour le règlement des différends relatifs aux investissements entre Etats et ressortissants d'autre Etats, in: 93 Journal du Droit Interrelational, Clunet, No. 1, S. 26-49 (1966); ders., Convention on the Settlement of Investment Disputes between States and Nationals of Other States, in: International Lawyer, Journal of the ABA Section on International and Comparative Law, No. 1, S. 64-80 (1966); E. Lauterpacht, The World Bank Convention on the Settlement of International Disputes, in: Recueil d'Etudes de Droit International en Hommage à Paul Guggenheim (1968), S. 642-664; Eugenio Minoli, Osservasioni sul Recente Progretto della Banca Internationale di Riconstruzione e Sviluppo per la Risoluzione Internazionale di Controversie, in: Rivista dell' Arbitrato No. 3, S. 113-120 (1965); Nigel S. Rodley, Some Aspects of the World Bank Convention on the Settlement of Investment Disputes, in: 4 Canadian Yearbook of International Law (1966), S. 43-63; Jean-David Roulet, Convention pour le Règlement des Différends Relatifs aux Investissements, in: Revue Suisse de Jurisprudence, 15. Okt. 1965, S. 301-305; ders., La Convention du 18 mars 1965 pour le règlement des différends entre États et ressortissants d'autres Etats, in: XXII Annuaire Suisse de Droit International (1965), S. 121-154; David Sassoon, Convention on the Settlement of Investment Disputes, in Journal of Business Law (1965), S. 334-339; ders., The Convention on the Settlement of Investment Disputes between States and Nationals of Other States, in: Israel Law Review No. 1 (1966), S. 27-39; Josef P. Sirefman, The World Bank Plan for Investment Dispute Arbitration, in: 20 Arbitration Journal No. 3 (1965), S. 168-178; sowie die im ersten Jahresbericht des Zentrums angeführte Literatur. ICSID, First Annual Report 1966/1967, S. 18.

2 Die Konvention selbst vermeidet eine Definition des Begriffes „Investition“. Von Schelling versteht darunter jegliche Vermögensanlage (bewegliches und unbewegliches Vermögen, Konzessionen, Beteiligungen, Wertpapiere, Forderungen und Rechte) in einem anderen Lande als dem, in dem der Investor seinen Wohnsitz hat", Wörterbuch des Völkerrechts, Bd. II, S. 149. Um Mißverständnisse in Hinblick auf Wohnsitz hat", Worterbuch des Völkerrechts, Bd. II, $\mathrm{S}$. 149. Um Mißverstandnisse in Hinblick auf
föderalistisch organisierte Staaten zu vermeiden, wäre vielleicht der Ausdruck "Staat" dem des "Landes" vorzuziehen gewesen. Section 223 (a) des US-Investitionsförderungsgesetzes 1961 (Act for International Development) definiert den Begriff wie folgt: "(investment shall include) ... any contribution of capital commodities, services, patents, processes or techniques in the form of:

(1) a loan or loans to an approved project;

(2) the purchase of a share of ownership in any such project;

(3) participation in royalties, earnings or profit of any such project;

(4) the furnishing of capital commodities and related services pursuant to a contract providing for payment in whole or in part after the end of the fiscal year in which the guaranty of such investment is made."

Zitiert bei Nwogugu, The Legal Problems of Foreign Investment in Developing Countries (1965), S. 71 Vgl. dazu die in einer Reihe von Investitionsförderungsverträgen zwischen der Bundesrepublik Deutschland Vertrages mit der Republik Kolumbien vom 11. Juni 1965: „1) Der Ausdruck ,Kapitalanlagen' umfaßt alle Vermögenswerte, insbesondere, aber nicht ausschließlich:

a) Eigentum an beweglichen und unbeweglichen Sachen sowie sonstige dingliche Rechte wie Hypotheken, Pfandbriefe oder dergleichen;

b) Anteilsrechte an Gesellschaften und andere Arten von Beteiligungen; 
treten und im allgemeinen als Investitionsstreitigkeiten bezeichnet werden. Dabei können als Entstehungsursache solcher Streitigkeiten Meinungsverschiedenheiten über die Anwendung oder Auslegung des der Investition zugrundeliegenden Vertrages (z. B. Konzessionsvertrag) in Betracht kommen; ebenso könnte z. B. die Durchführung innerstaatlicher Investitionsförderungsgesetze Anlaß zur Entstehung von Streitigkeiten geben und schließlich wären als klassische Fälle von Investitionsstreitigkeiten Enteignungs- oder Nationalisierungsmaßnahmen des Anlagestaates zu nennen. Das Fortbestehen solcher Streitigkeiten mangels geeigneter Wege zu deren Beilegung bleibt zumeist nicht ohne Einfluß auf die wirtschaftliche Entwicklung eines auf privates Auslandskapital angewiesenen Landes, da solche Faktoren in die Risikokalkulation potentieller Investoren miteinbezogen werden. Nach den Intentionen der Schöpfer der Konvention ${ }^{3}$ sollten nun die geschaffenen Einrichtungen eine Verbesserung des Investitionsklimas bewirken und dazu beitragen, den Strom privaten Kapitals in jene Staaten zu lenken, die danach verlangen und auf der anderen Seite bereit sind, durch Annahme der vorgesehenen und im einzelnen $\mathrm{zu}$ untersuchenden Streitbeilegungswege das Risiko der privaten Auslandsinvestition $\mathrm{zu}$ verringern. Wirtschaftliche Motive standen somit für die juristische Gestaltung der Streitbeilegungsinstitutionen im Vordergrund.

Zum zweiten ist hervorzuheben, daß hier auf multilateraler Ebene erstmalig in der Geschichte der internationalen Schiedsgerichtsbarkeit ständige, d.h. jederzeit den Parteien auf Wunsch zur Verfügung stehende Streitbeilegungsinstanzen (i. s. Vergleichskommission und Schiedsgericht) geschaffen wurden, vor welchen Einzelpersonen und Staaten in prozessualer Hinsicht gleichberechtigt einander gegenüberstehen. Im traditionellen System der internationalen Schiedsgerichtsbarkeit wurde dem Individuum - von im einzelnen noch $\mathrm{zu}$ besprechenden Ausnahmen abgesehen - eine passive Rolle zugewiesen und die Geltendmachung des Anspruches auf internationaler Ebene dem Heimatstaat des in seinen Rechten verletzten Individuums überlassen; dagegen räumt die Konvention der Einzelperson ein direktes Zugangsrecht $\mathrm{zu}$ internationalen Instanzen ein und versucht auf diese Weise, den Streit auf wirtschaftlich-rechtlicher Basis zu begrenzen und dadurch die Entstehung eines durch das Hinzutreten des Heimatstaates des Investors bewirkten politischen und internationalen Streitfalles zu verhindern.

Gegenstand der vorliegenden Untersuchung ist es, zunächst unter dem Aspekt der prozessualen Stellung des Individuums vor internationalen Rechtssprechungsinstanzen die traditionellen Streitbeilegungsmethoden von Investitionsstreitigkeiten in historischer Sicht $\mathrm{zu}$ beleuchten, sodann die Konvention selbst im einzelnen $\mathrm{zu}$ erörtern und abschließend - im besonderen dem Anliegen dieser Zeitschrift entsprechend - die Reaktion der neuen Staaten in Übersee auf die durch die Konvention geschaffenen Einrichtungen aufzuzeigen.

\footnotetext{
c) Ansprüche auf Geld oder Leistungen, die einen wirtschaftlichen Wert haben;

d) Urheberrechte, Rechte des gewerblichen Eigentums, technische Verfahren, Handelsnamen und good will; e) öffentlich-rechtliche Konzessionen, einschließlich Aufsuchungs- und Gewinnungskonzessionen ....". (BGBI. 1967 II S. 1555).

$3 \int 9$ des Berichtes des Direktoriums der Weltbank. Sowie anläßlich der Gründung der IFC und der IEO war auch hier die den Regierungen der Mitgliedstaaten der Weltbank vorgelegte Konvention von einem Bericht des Direktoriums (im folgenden "Bericht" ${ }^{\prime}$ genannt) begleitet, welchem $\mathrm{zwar}$ keine rechtliche Verbindlichkeit zukommt, aber zu Interpretationszwecken herangezogen werden kann.
} 


\section{Die Problematik der traditionellen Methoden zur Beilegung von Investitions-}

streitigkeiten zwischen Staaten und Einzelpersonen durch isolierte Schiedsgerichte

Die industrielle Revolution und der Stand der Kapitalwirtschaft zu Beginn des vergangenen Jahrhunderts bedingten das Bestreben von Privatpersonen oder Gesellschaften, Kapital in fremden Staaten gewinnbringend zu investieren. Diesem Ziel dienten die nunmehr erworbenen technischen Erkenntnisse und Mittel, die Angehörige vor allem der Industriestaaten, Großbritannien und später der Vereinigten Staaten, Frankreichs und des Deutschen Reichs, in die Lage versetzten, dieselben im Bereiche des Verkehrswesens und der Erschließung von Rohstoffquellen in jenen Staaten einzusetzen, die selbst dazu noch nicht in der Lage waren. Als rechtliche Basis für solche Unternehmen dienten zunächst zwischen dem Anlagestaat und dem Heimatstaat des Investors abgeschlossene Handels- und Schiffahrtsverträge ${ }^{4}$, die im allgemeinen auch Bestimmungen über das Niederlassungsrecht der gegenseitigen Staatsangehörigen verbunden mit einer Meistbegünstigungsklausel enthielten. Später wurden zwischen dem Anlagestaat und dem ausländischen Investor auf gleicher Basis Verträge abgeschlossen, durch die letzterem bestimmte, in der Regel nur dem Staat zustehende Rechte eingeräumt wurden, und die im allgemeinen als Konzessionsverträge bezeichnet werden ${ }^{5}$.

Wurde der ausländische Investor durch Akte des Anlagestaates in seinen Rechten verletzt, so stand ihm zunächst die Rechtsverfolgung im Wege der Rechtsschutzinstanzen des Anlagestaates offen. Aussichtslos erschien dieses Unternehmen dann, wenn der angefochtene rechtswidrige Akt in Gestalt eines Gesetzes oder eines keiner weiteren Überprüfung unterliegenden Verwaltungsaktes (z. B. Dekret) ergangen war. In einem solchen Falle blieb dem verletzten Individuum nur die Möglichkeit, sich an seinen Heimatstaat $\mathrm{zu}$ wenden, der in Ausübung seines diplomatischen Schutzrechtes den Rechtsanspruch seines Staatsangehörigen gegenüber dem Anlagestaat auf völkerrechtlicher Ebene geltendmachen konnte; für den Heimatstaat entstand daraus jedoch noch keine Verpflichtung, sondern es war seinem Ermessen anheimgestellt, den Anspruch seines Staatsangehörigen zur Gänze oder auch nur teilweise ${ }^{6}$ vorzubringen oder überhaupt jedes Tätigwerden gegenüber dem Anlagestaat zu verweigern. Gründe dafür waren zumeist politischer Natur, da etwa eine Verschlechterung des politischen Klimas zwischen den beiden Staaten vermieden oder die eigenen Staatsangehörigen zu Investitionen im eigenen Staat angehalten werden sollten ${ }^{7}$. Erschien hingegen dem Heimatstaat die Geltendmachung des Anspruches seines Staatsangehörigen gegenüber dem Anlagestaat als politisch opportun, so zeigte gerade die Praxis im lateinamerikanischen Bereich, daß dann häufig die schmale Grenze zwischen diplomatischer Vorstellung und

4 Vgl. MI. de Taube, Traités internationaux. I - Historique et caractère obligatoire. Dictionnaire Diplomatique, Bd. 2 (1939), S. $954 \mathrm{ff}$.

$5 \mathrm{Vgl}$. als frühes Beispiel den vorläufigen Konzessionsvertrag zwischen Ferdinand de Lesseps und dem Vizekönig von Agypten, Said Pascha, vom 30. November 1854 über den Bau und den Betrieb des Suezkanals. Hierzu R. Dedreux, Der Suezkanal im internationalen Recht (1913). Dazu unten S. 269.

6 Wenn sich der Heimtstaat z. B. mit einem Bruchteil der Entschädigungssumme bei Enteignungen begnügt. Vgl. dazu Seidl-Hohenveldern, Judicial Protection of Foreign Investments, in: Mélanges Séfériadès (1961), S. 255.

7 Vgl. die berühmte Instruktion Lord Palmerstons an die britischen Vertreter in fremden Staaten (1848): "It has hitherto been thought by the successive Governments of Great Britain undesirable that British subjects should invest their capital in loans to foreign governments instead of employing it in profitable undertakings at home; and with a view to discourage hazardous loans to foreign governments, who may be either unable or unwilling to pay the stipulated interest thereupon, the British Government has hitherto thought it the best policy to abstain from taking up as international questions the complaints made by British subjects against foreign governments which have failed to make good their engagements in regard to such pecuniary g o ve r n m e n t $s$ which have faled to make good their engagements in regard to such pecuniary transactions. (Sperrung von uns.) Zitiert bei Jennings, State Contracts in International Law, in:
Selected Readings on Protaction by Law of Private Foreign Investments, International and Comparative Law Centre, The Southwestern Legal Foundation, Dallas, Texas (1964), S. 179. 
Intervention überschritten wurde ${ }^{8}$. Als Reaktion auf diese Entwicklung entstand hier die sogenannte Calvo-Doktrin, die später in Gestalt der Calvo-Klausel in die Verträge zwischen Anlagestaat und ausländischem Investor eingefügt wurde und auch heute noch keineswegs an Bedeutung eingebüßt hat ${ }^{9}$.

In Anbetracht der Komplexität der mit Investitionsstreitigkeiten verbundenen wirtschaftlichen und rechtlichen Problemen wurde eine befriedigende Beilegung auf diplomatischem Wege nur in seltenen Fällen erreicht, weil nicht zuletzt der individuelle Anspruch nahezu immer die Höhe des wahren Schadens überstieg ${ }^{10}$. Aus diesen Gründen erschien die Einsetzung einer unparteiischen Schiedsinstanz, welche den Erfordernissen der Materie Rechnung tragen und eine objektive Schadensbemessung gewährleisten konnte, schon im frühen 19. Jahrhundert als geeigneter Weg zur Beilegung solcher Streitigkeiten. Insbesondere in der angloamerikanischen Praxis wurden Schiedsgerichte in Gestalt der nach dem Vorbild des Jay-Vertrages von $1794^{11}$ errichteten Claims Commission gebildet. Solche Claims Commissions wurden durch Vertrag zwischen beiden an einer schiedsgerichtlichen Beilegung interessierten Staaten errichtet und hatten über die gegenseitigen Ansprüche der Staatsangehörigen der das Schiedsgericht errichtenden Staaten gegenüber dem anderen Staat ${ }^{12} z u$ entscheiden. Als Ausfluß des völkerrechtlichen Grundsatzes der Mediatisierung des Einzelmenschen blieb dabei in der Regel der Individualanspruch gegenüber dem fremden Staat ganz der verfahrensrechtlichen Kontrolle des Heimatstaates unterworfen: er wurde von diesem vor der Schiedsinstanz „on behalf of its national“ geltend gemacht, der Schiedsspruch lautete nicht zu Gunsten des geschädigten Individuums, sondern zu Gunsten des Staates und die Entschädigungssumme wurde nicht dem Individuum entrichtet, sondern dem Heimatstaat zumeist im Wege des diplomatischen Verkehrs übergeben ${ }^{13}$. Prozeßpartei waren lediglich die beiden Staaten, die Einzelpersonen oder Gesellschaft spielte eine passive Rolle. Sie war an dem Streit als solchem nicht direkt beteiligt. Anders lag der Fall, wenn a u $\mathrm{n}$ a h $\mathrm{ms}$ we is e die das internationale Schiedsgericht begründende Staaten auf das Recht zur prozessualen Geltendmachung von Ansprüchen ihrer Staatsangehörigen verzichtet hatten. Gewöhnlich kann auf einen solchen Verzicht durch die im Kompromissum der Einzelperson gewährte Befugnis auf persönliche Geltendmachung des Anspruches sowie auf Wahl eines Rechtsvertreters vor der Kommission geschlossen werden. Auch die Formulierung des Streit-

$8 \mathrm{Vgl}$. die Blockade Venezuelas durch Großbritannien, dem Deutschen Reich und durch Italien zu Beginn dieses Jahrhunderts. Dazu L. Kotsch, Die Blockade gegen Venezuela vom Jahre 1902 als Präzedenzfall für das moderne Kriegsrecht, in: ArchVR 5 (1955/56), S. $410 \mathrm{ff}$.

9 Dazu R. Shea, The Calvo Clause. A Problem of Inter-American and International Law and Diplomacy. University of Minnesota Press (1955). Siehe auch unten S. 300.

$10 \mathrm{Vgl}$. den noch $\mathrm{zu}$ erwähnenden Sizilianischen Schwefelmonopol-Fall, in welchem alle geschädigten Einzelpersonen weit übertriebene Forderungen gestellt hatten. Dazu unten S. 266.

11 Hierzu Schlochauer, Wörterbuch des VR, Bd. II, S. $170 \mathrm{ff}$.

12 Von "General“ Claims Commissions wird dann gesprochen, wenn Staatsangehörige beider Vertragsstaaten zur Geltendmachung von Ansprüchen berechtigt sind, während vor "Special“ Claims Commissions nur Angehörige einer Vertragspartei Zugang haben. Vgl. Mexican Special und Mexican General Claims Commissions. Stuyt, Survey of International Arbitrations 1794-1938, The Hague (1939), im folgenden "Stuyt" und die Nummer des Schiedsfalles zitiert. Nr. 355 und Nr. 354. Ihrer Zusammensetzung nach "waren sie zumeist entweder "Joint" oder "Mixed" Commissions, je nachdem, ob sie aus einer gleichen Anzahl nationaler Schiedsrichter bestanden, oder ob neben nationalen Schiedsrichtern darüber hinaus ein Anzahl nationaler Schiedsrichter bestanden, oder ob neben nationalen Schiedsrichtern darüber hinaus ein
Angehöriger eines am Streit nicht beteiligten Staates als Obmann (umpire, sur-arbitre, président) in das Schiedsgericht berufen wurde. Vgl. Hudson, International Tribunals - Past and Future (1944), S. 122 ff.

13 Repräsentativ für viele ist die Entscheidung der (Mexican) General Claims Commission im Fall der Illinois Central Railroad: ". . . the claim was originally made by the United States of America o $n$ $\mathrm{b}$ e ha $1 \mathrm{f}$ of the Illinois Central Railroad... the Government of Mexico shall pay to the Gove $\mathrm{r} n$ ment of $t$ he United State $s$ the sum of ..." (Sperrung von uns.) U.N.R.I.A.A., Bd. IV, S. 134 und 137. Vgl. auch Art. VII des Kompromissums zwischen Guatemala und Mexico vom 26. Januar 1888: "Cada Gobierno podrá nombrar una persona para que, ob $\mathrm{r}$ a n d o e n s u n o m b re, presente y apoye reclamaciones, responda a las que se hicieron contra él, y lo represente en general en todos los asuntos relacionados con el exanien y fallo de las mismas." (Sperrung von uns.) La Fontaine, Pasicrisie Internationale, Berne (1902), S. $\vdots 26$. 
gegenstandes (subject-matter) kann darüber Aufschluß geben ${ }^{14}$. Lautet darüber hinaus der Schiedsspruch ausschließlich auf den Namen der Einzelperson, so kann es bei Vorliegen der genannten Kriterien kaum mehr Zweifel geben, daß die das Schiedsgericht begründenden Staaten Einzelpersonen oder Gesellschaften eine mehr oder minder beschränkte Partei- und Prozeßfähigkeit einzuräumen beabsichtigten.

Ein frühes Beispiel einer Investitionsstreitigkeit unter Gewährung einer solchen beschränkten prozessualen Rechts- und Handlungsfreiheit an physische und juristische Personen stellt der bisher kaum beachtete Sizilianische Schwefelmonopol-Fall zwischen Großbritannien und dem Königreich Beider Sizilien dar. Die durch Vertrag vom 17. November $1840^{15}$ errichtete Kommission hatte über im Kompromissum materiell spezifizierte ${ }^{16}$ Rechtsansprüche von Einzelpersonen und Gesellschaften britischer Nationalität zu entscheiden, welche durch ein Dekret des Königs Ferdinand II. von Neapel in ihrer wirtschaftlichen Tätigkeit, die auf Gewinnung und Ausfuhr von Schwefel gerichtet war, Schäden erlitten hatten. Dieses Dekret räumte in Widerspruch zu dem mit Großbritannien 1816 abgeschlossenen Handels- und Schiffahrtsvertrag17 der französischen Gesellschaft Taix, Aycard \& Cie ein Exportmonopol für sizilianischen Schwefel ein. Gemäß den Bestimmungen des Kompromissums konnten die geschädigten Einzelpersonen ihren Anspruch gegenüber dem Königreich Sizilien unter Beibringung der erforderlichen Beweismittel direkt vor der Schiedsinstanz geltend machen. Der individuelle Schiedsspruch lautete auf den Namen der geschädigten Person oder Gesellschaft; er wurde in Form eines verzinslichen Wertpapieres ${ }^{18}$ ausgefertigt und mußte nach den Bestimmungen des Kompromissums innerhalb eines Jahres vom Königreich Sizilien eingelöst werden. Die Funktion des Heimatstaates beschränkte sich somit auf die Errichtung einer internationalen Rechtssprechungsinstanz. Er nahm keinen wie immer gearteten Einfluß auf das anhängige Schiedsverfahren, dem Individuum wurde direkter Zugang zu einem internationalen Schiedsgericht eingeräumt, und die Rolle des Heimatstaates trat vollständig in den Hintergrund.

Die Anführung weiterer Beispiele von prozessualen Individualrechten vor internationalen Schiedsgerichten würde den Rahmen der gegenständlichen Untersuchung sprengen ${ }^{19}$. Festzuhalten sei nur, daß bereits in der Ad-hoc-Schiedsgerichtspraxis des 19. Jahrhunderts Ansätze zu einer beschränkten internationalen Partei- und Prozeßfähigkeit von Einzelpersonen nachgewiesen werden können. Hier lediglich den beiden, das Schiedsgericht errichtenden Staaten eine Parteifähigkeit zuzuerkennen, wäre eine Generalisierung, die einer näheren Untersuchung kaum standhältt ${ }^{20}$.

14 Wird z. B. lediglich die Einzelperson (Gesellschaft) als Anspruchsberechtigte im Kompromissum genannt, wie es in der häufigsten Formulierung "... all claims on the part of corporations, companies, or private individuals ..." der Fiall ist, so kann unter Umständen auf einen solchen Verzicht geschlossen werden; vgl. die Fälle Stuyt Ni. 55, 65, 68, 71, 78, 82, 84 und dergleichen mehr.

$15 \mathrm{La}$ Fontaine, a. a. O., S. 97.

16 Absatz 3 des Vertrages zählt erschöpfend die Kategorien der Ansprüche (classes of claims) auf. Loc. cit., S. 97.

17 Außenminister Viscount Palmerston an den britischen Vertreter W. Temple in Neapel, 27. Oktober 1837. Parl. Pap. Vol. XLIV (1840), S. 452.

18 Minute of the closing of the Commission. 24. Dezember 1841. Abgedruckt bei La Fontaine, a. a. O., S. 99.

19 Vgl. hierzu: United States and Paraguay Navigation Co. v. Paraguay in Lapradelle-Politis, Recueil des Arbitrages Internationaux, Bd. II, S. $45 \mathrm{ff}$; w weiter die Schiedspraxis nachstehender Schiedsgerichte: USA-Großbritannien (8. Februar 1853), Stuyt, a. a. O., Nr. 47; Ekuador-USA (25. November 1862), Stutyt, a. a. O., Nr. 68, und La Pradelle-Politis, a. a. O., S. 422 ff.; USA-Großbritannien (1. Juli 1863), im Fall Hudson Bay Co., Stutyt, Nr. 73, und La Pradelle-Politis, a. a. O., S. 503 ff.; Großbritannnien-Venezuela (21. September 1868), Stuyt, Nr. 83, und La Pradelle-Politis, a. a. O., S. 524 ff.; USA-Peru (4. Dezember 1868), Stuyt, Nr. 84, und La Pradelle-Politis, a. a. O., S. 583 ff. Die Daten

20 in Klammern bestimmen sich nach dem Abschluß des Kompromissums. Access of Individuals to International Courts, in: 24 AJIL (1930), S. 359, Partsch, in Wörterbuch des Aölkerrechts, Bd. II, S. 14, Dahm, Völkerrecht (1961), Bd. II, S. 500 ff., F. A. von der Heydte, L'Individu et les tribunaux internationaux, in: Rec. des Cours III (1962), und die dort angeführte 
Das erste echte Klagerecht vor einem internationalen Gericht wurde Einzelpersonen durch Art. II der „Konvention zur Errichtung eines Zentralamerikanischen Gerichtshofes" vom 20. Dezember 1907 eingeräumt. Während des kurzen Bestandes dieses Gerichtshofes wurden ihm fünf Fälle unterbreitet, die Einzelpersonen gegen einen Mitgliedstaat unter der genannten Bestimmung der Konvention anhängig gemacht haben; allerdings war in keinem der Fälle der klagenden Privatperson ein Erfolg beschieden ${ }^{21}$.

Die durch die Pariser Friedensverträge errichteten Gemischten Schiedsgerichte $^{22}$ sowie das durch den Deutsch-Polnischen Vertrag vom 15. Mai 1922 geschaffene Schiedsgericht für Oberschlesien² ließen gleichfalls Individualklagen in dem durch das konstituierende Instrument gesetzten Rahmen zu. Im Falle Steiner \& Groß gegen Polnischen Staat anerkannte das Schiedsgericht für Oberschlesien einen Klageanspruch sogar gegen den Heimatstaat des verletzten Individuums. In jüngerer Vergangenheit sind es die Bonner Verträge, die nach dem Vorbild des Vertrages von Versailles die Errichtung einer Schiedskommission vorsehen, welche auch Einzelpersonen zugänglich sein sollte ${ }^{24}$.

Während in den genannten Beispielen die zur Entscheidung zwischen Staat und Einzelperson berufene internationale Instanz durch einen völkerrechtlic h e n Vertrag zwischen Staaten errichtet wurde, können in der Praxis der schiedsgerichtlichen Beilegung von Investitionsstreitigkeiten auch solche Fälle nachgewiesen werden, in welchen es zur Bildung eines Schiedsgerichtes durch Vertrag unmittelbar zwischen dem Investor und dem Anlagestaat gekommen ist ${ }^{26}$. Solche Schiedsgerichte können nun keineswegs als innerstaatliche Rechtssprechungsinstanzen etwa des Anlagestaates qualifiziert werden ${ }^{27}$, denn sowohl die Zusammensetzung des Gerichts, die den Mixed Commissions angepaßt ist ${ }^{28}$, als auch das Verfahren zur Errichtung derselben ${ }^{29}$ lassen kaum Zweifel, daß die Parteien bewußt

Literatur; hingegen Schlochauer lehnt eine mögliche Parteifähigkeit anderer Völkerrechtssubjekte als Staaten sowie von Einzelpersonen vor internationalen Schiedsgerichten generell ab. Wörterbuch des Völkerrechts, Bd. III, S. 185.

21 Stuyt, a. a. O., S. 400. Vgl. den Fall Diaz v. Guatemala, 3 AJIL (1909), S. 737. Allgemein: Anales de la Corte de Justicia Centro-Americana 1911-1917. Kraske, Der Mittelamerikanische Gerichtshof, ArchVR 2 (1948/50), S. $204 \mathrm{ff}$.

22 Stuyt, Nr. 325 und 326.

23 Stuyt, Nr. 345. Dazu Kaeckenbeeck, International Experiment in Upper Silesia (1942)

24 Art. 6 Abs. 4 der Satzung der Schiedskommission für Güter, Rechte und Interessen in Deutschland. Anhang zum Vertrag zur Regelung aus Krieg und Besatzung entstandener Fragen vom 26. Mai 1952 in der Fassung vom 23. Oktober 1954. Abgedruckt in Mosler, Materialien 1 (Internationale Gerichte und Schiedsgerichte), S. 280. Dazu auch Partsch, a. a. O., S. 12. Hingegen schafft Art. 25 der Konvention zum Schutze der Menschenrechte und Grundfreiheiten (abgedruckt in Mosler, a. a. O., S. 116) der Einzelperson kein Zugangsrecht zum Gerichtshof, sondern die Kommission, die in der Folge als Prozeßpartei auftritt (Art. 44), entscheidet über eine etwaige Befassung des Gerichtshofes mit der Individualbeschwerde. Vgl. die Entscheidung des Gerichtshofes im De-Becker-Fall: “. . a an idividual who has lodged an application with the Comission has no right to bring a case before the Court...", in: I. L. R., Bd. 33 (1967), S. 228.

26 Rechtsgrundlage ist hier zumeist eine Schiedsklausel des Konzessionsvertrages, die durch ein nach Entstehung des Streitfalles abzuschließende Kompromissum, welches insbesondere Bestimmungen über die dem Schiedsgericht vorzulegenden Fragen, über das anwendbare Recht und Verfahrensvorschriften enthält, näher ausgeführt wird. Vgl. das in Durchführung von Art. 31 des "ARAMCO-Concession Agreement abgeschlossene "Arbitration Agreement ${ }^{*}$ vom 23. Februar 1955, in: ILR, Bd. 27 (1963), S. $229 \mathrm{f}$.

27 Bestritten von Mann, welcher zumindest die Fälle Radio Corporation of America v. China (3 U.N.R.I.A.A., S. $1623 \mathrm{ff}$.) und The Administration of Posts and Telegraphs of the Republic of Czechoslovakia v. Radio Corporation of America (Stuyt, Nr. 385) als rein privatrechtlicher Natur ansieht; State Contracts and State Responsibility, in: 54 AJIL (1960), S. 580, Fußnote 43.

28 Dazu siehe oben S. 265. Gelegentlich wurde auch eine international anerkannte Persönlichkeit zum Einzelschiedsrichter berufen; dazu siehe unten S. 269 und 271.

29 In vielen Schiedsklauseln in Konzessionsverträgen ist die Bestimmung.enthalten, daß bei Nichteinigung über die Person des(r) Schiedsrichter(s) eine international als unparteiisch anerkannte Persönlichkeit die Nominierung vornehmen sollte. So z. B. Art. 41 des Vertrages $z$ wischen der persischen staatlichen Erwerbsgesellschaft NIOC und der Pan American Petroleum Corporation vom 24. April 1958, und Art. 41 des Vertrages $z$ wischen der NIOC und der kanadischen Gesellschaft Sapphire Petroleum Ltd. vom 16. Juni 1958, welche Bestimmung dem Präsidenten des Schweizer Bundesgerichtes dieses Recht zuweist; letztere kam im Sapphire-Fall bald zur Anwendung und der Präsident bestellte den Bundesrichter M. Pierre Cavin zum "arbitre unique“. Dazu P. F. Lalive, Un recent arbitrage suisse entre un organisme d'Etat et une société privée étrangère, in: Annuaire Suisse de D. I. (1962), S. $273 \mathrm{ff}$. Auch der Präsident des Internationalen Gerichtshofes wird häufig zur Ernennung von Schiedsrichtern delegiert: so z. B. Art. 44 des Vertrages zwischen NIOC und dem Olkonsortium (bestehend u. a. aus der British Petrol Co., der Royal Dutch Shell, Gulf Oil, Socony Mobil usw.) vom 21. Oktober 1954; Art. 39 des Vertrages 
die Zuständigkeit innerstaatlicher Instanzen ausschließen wollten. Diese formellen Kriterien in Verbindung mit dem Inhalt des Streitgegenstandes, der der Natur von Konzessionsverträgen dieser Art entsprechend sowohl privatrechtlichen als auch öffentlich-rechtlichen Charakter besitzt und internationale Interessen berührt ${ }^{30}$, sind hinreichende Kriterien für den extranationalen Charakter dieser Rechtssprechungsinstanzen ${ }^{31}$. S $\mathrm{r}$ i c t u se $\mathrm{n} \mathrm{u}$ handelt es sich jedoch damit noch nicht um „internationale“ Schiedsgerichte, zu deren Errichtung das Zusammenwirken von Völkerrechtssubjekten Voraussetzung ist, sondern um eine Zwischenform, so daß der von Verdross geprägte Terminus der "quasi-völkerrechtlichen“ Schiedsinstanz dafür als geeignet erscheint ${ }^{32}$.

An dieser Stelle kann nicht auf die eng damit verbundene Frage der Grundlegung des Verhältnisses Staat und Investor eingegangen werden, welche seit über einem Jahrzehnt Gegenstand der wissenschaftlichen Diskussion ist ${ }^{\mathbf{3}}$; doch es darf bemerkt werden, daß das Vorhandensein einer Schiedsklausel in einem Konzessionsvertrag, die für den Fall einer Streitigkeit die Errichtung einer quasi-völkerrechtlichen Schiedsinstanz vorsieht, das wesentlichste Kriterium für jene rechtstheoretischen Auffassungen bildet, die entweder eine Rechtsgemeinschaft sui gen e ris annehmen oder überhaupt das Rechtsverhältnis zwischen Anlagestaat und ausländischem Investor der Völkerrechtsordnung direkt unterstellen ${ }^{34}$.

Die Errichtung quasi-völkerrechtlicher Schiedsgerichte als Methode zur Beilegung von Investitionsstreitigkeiten ist nun keineswegs, wie vielfach angenommen wird ${ }^{\mathbf{3 5}}$,

zwischen NIOC und einem Konsortium amerikanischer Olgesellschaften wie Tidewater Oil Co., Skelly Oil Co., Sunray DX Oil Co., The Superior Oil Co., usw., vom 16. Januar 1965; Art. 28 des Vertrages $\mathrm{z}$ wischen Saudi-Arabien und der Trans-Arabian Pipe Line Company (TAPLINE) vom 11. Juli 1947; Art. 55 des Vertrages zwischen Saudi-Arabien und der Japan Petroleum Trading Company Ltd. vom 10. Dezember 1957 spricht - wohl irrtümlich - von einem Ernennungsersuchen an den Präsidenten des $\mathrm{S} t$ ä n d i g e $n$ Internationalen Gerichtshofes (siehe S. $30 \mathrm{der} 1958$ in Kairo, Imprimerie MISR. S. A. E., gedruckten Ausgabe); Art. 7 (c) des Ergänzenden Vertrages zwischen Kuwait und den drei Gesellschaften BP (Kuwait) Ltd., Gulf Kuwait Company und der Kuwait Oil Company vom 19. November 1966, in Kuwait Al Youm - P. 2 - Appendix No. 633, S. 3; Art. 11 des Ergänzenden Vertrages zwischen Qatar und der Qatar Petroleum Company Ltd. vom 31. Dezember 1964 weist auch das Ernennungsrecht dem Präsidenten des Internationalen Gerichtshofes zu, doch sollte dieser ein Staatsangehöriger der Vereinigten Staaten, Großbritanniens, Frankreichs, Hollands, Portugals oder Panamas sein, dann geht dieses Recht auf den Präsidenten des Schweizer Bundesgerichtes über. Vgl. weiter Art. 35 des Vertrages zwischen der irakischen staatlichen Gesellschaft INOC und der französischen Gesellschaft ERAP vom 3. Februar 1968. Dazu unten (Dokumentation), S. 332.

30 So auch La Pradelle, a. a. O., S. 376, der von einem "intérêt cosmopolite du litige “ spricht.

31 Bestimmungen hinsichtlich des anwendbaren Rechts hingegen scheinen als Kriterium für den internationalen oder quasi-internationalen Charakter einer Rechtsprechungsinstanz weniger geeignet, denn sowohl innerstaatliche Gerichte können Völkerrecht, als auch völkerrechtliche Gerichte innerstaatliches Recht zur staatliche Gerichte können Volkerrecht,
Anwendung bringen. Dazu unten S. 272 .

32 The Status of Foreign Private Interests Stemming from Economic Development Agreements with Arbitration Clauses, in: Osterreichische Zeitschrift für Offentliches Recht, Bd. IX (1958/59), S. 456.

$33 \mathrm{Es}$ ist das Verdienst Verdross, als erster auf diese Erscheinung hingewiesen und eine systematische Einordnung versucht $\mathrm{zu}$ haben; siehe Die Sicherung von ausländischen Privatrechten aus Abkommen zur wirtschaftlichen Entwicklung mit Schiedsklauseln, in Zeitschrift f. a. ö. RuVR 18 (1958), S. 635-651 (vgl. FN 32); ders.: Gibt es Verträge, die weder dem innerstaatlichen noch dem Völkerrecht unterliegen?, in Zeitschrift für Rechtsvergleichung 3/4 (1965), S. 129 ff.; ders.: Quasi-international agreements and international transactions, in: Yearbook of World Affairs 1964, Bd. 18, S. 230 ff.; Protection of Private Property under Quasi-International Agreements, in: Liber Amicorum, J. P. A. Francois, Leyden 1959, S. $355 \mathrm{ff}$.; Kipp führt dessen Thesen näher aus: Verträge $\mathrm{zwischen}$ staatlichen und nichtstaatlichen Partnern, in: Berichte der Deutschen Gesellschaft für Völkerrecht, Heft 5 (1964), S. 133-188, und die dort angeführte Literatur; Garcia-Amador, $L$ a responsibilité international des Etats, in: Rapports à la Comission du Droit International, 4e Rapport, Ann. C. D. I. 1959, II, S. 1-36; Hyde, Economic Development Agreements, Rec. des Cours I (1962), S. $267 \mathrm{ff}$.; Bourquin, Arbitration and Economic Development Agreements, in: The Business Lawyer (1960), S. $860 \mathrm{ff}$.

$34 \mathrm{Zu}$ ersteren zählen vor allem Verdross (siehe vorhergehende Fußnote); ebenso Zemanek, welcher sich gegen die ausschließlich dualistische Konzeption der Rechtsauffassung wendet, siehe: Uber das dualistische Denken in der Völkerrechtswissenschaft, in: Völkerrecht und rechtliches Weltbild, Festschrift für Alfred Denken in der Vökerrechtswissenschaft, in: Vökerrecht und rechtich
Verdross (Wien 1960), S. 332; Kipp, a. a. O., und Bourquin, a. a. O.

Zu letzterer Gruppe: Lord McNair, The General Principles of Law recognized by Civilized Nations, in: XXXIII BYIL (1957), S. 1-19; Bindschedler und von der Heydte in der Diskussion in der Deutschen Gesellschaft für Völkerrecht am 30. April 1963, a. a. O., S. $232 \mathrm{ff}$.; vgl. hierzu auch die Beiträge von Carlston, Wehberg, Domke, Ray und Seidl-Hohenveldern, in: Selected Readings on Protection by Law of Private Foreign Investments, International and Comparative Law Center, The Southwestern Legal Foundation, Dallas, Texas (1964).

Mann hingegen vertritt in jüngerer Zeit die These der Lokalisierung solcher Rechtsverhältnisse in der innerstaatlichen Rechtsordnung, die er ausschließlich unter dem Aspekt des Internationalen Privatrechtes beurteilt. Siehe dazu: Die Verträge der Völkerrechtssubjekte und die Parteiautonomie, in: Ius et Lex, Basel 1959, S. $477 \mathrm{ff}$.; ders.: The proper law of contracts concluded by international persons, in: XXXV BYIL (1959), S. $41 \mathrm{ff}$; ders.: State Contracts and State Responsibility, in: 54 AJIL (1960), S. 572 ff.

35 So u. a. F. Ssekandi, Contracts between a State and a Foreign Private Company, Reflections on the Effectiveness of the Arbitration Process, in: 2 East African Law Journal No. 4 (1966), S. 283. 
ein Phänomen, das mit dem berühmten Fall der Lena Goldfields Ltd. v. Union of Socialist Soviet Republics im Jahre $1930^{36}$ seinen Anfang genommen hat, sondern eine solche Erscheinung ist zumindest schon in der Mitte des 19. Jahrhunderts nachweisbar. Ein frühes Beispiel dieser Art ist der Fall der Compagnie du Canal de Suez v. Egypte, der hier zumindest kurze Beachtung finden muß.

Nachdem am 30. November 1854 zwischen Ferdinand von Lesseps und dem Vizekönig von Ägypten, Mohammed Said Pascha, ein vorläufiger Konzessionsvertrag zum Bau und Betrieb des Suezkanals durch eine noch zu gründende Gesellschaft abgeschlossen worden war, welcher durch die Konzessionsakte vom 5. Januar 1856 sowie durch das Règlement vom 20. Juli 1856 über die Verwendung von einheimischen Arbeitskräften ${ }^{37}$ modifiziert wurde, begann nach Gründung der „Compagnie universelle du canal de Suez", einer Gesellschaft ägyptischen Rechts mit Sitz in Alexandria, der Bau des Kanals im Jahre 1859. Der Nachfolger des am 18. Januar 1863 verstorbenen Said Pascha, Ismael Pascha, versuchte die umfangreichen territorialen Kontrollrechte der Gesellschaft einzuschränken und somit die Konzession bei gleichzeitiger Fortführung des Kanalbaues einseitig abzuändern. $\mathrm{Zu}$ diesem Zwecke veranlaßte er die Pforte, an die Höfe Londons und Paris eine gleichlautende Note zu richten, worin letztere erklärte, im Interesse der Wirtschaft des Landes das durch das genannte Règlement vereinbarte Kontingent von inländischen Arbeitskräften auf ein Viertel reduzieren sowie auf die Rückgabe der unter der Kontrolle der Gesellschaft stehenden Grenzgebiete Syriens und der Städte Suez, Timsah (das spätere Ismailia) und Port Said bestehen zu müssen ${ }^{38}$. Die Gesellschaft erklärte sich im Prinzip damit einverstanden, doch verlangte sie neben der Zustimmung zur Einstellung auch ausländischer Arbeitskräfte Schadenersatz in der Höhe von 50 Millionen Francs und den Verzicht der ägyptischen Regierung auf 15 Prozent der Nettoeinkünfte aus dem Kanalbetrieb ${ }^{39}$. Über diese Frage konnte jedoch keine Einigung erzielt werden; schließlich wurden durch Kompromissum vom 21. April 1864 zwischen der Gesellschaft und Ägypten diese Streitfragen Kaiser Napoleon III. als Schiedsrichter unterbreitet ${ }^{40}$, welcher durch Schiedsspruch vom 6. Juli $1864 \mathrm{zu}$ Gunsten der Gesellschaft erkannte und dieser die Summe von 84 Millionen Francs als Entschädigung für die rückübertragenen Gebiete und die durch den Wegfall der inländischen Arbeitskräfte verursachten Mehrkosten zusprach.

Dieser Schiedsspruch bildete die Grundlage für den am 22. Februar 1866 zwischen Ägypten und der Gesellschaft abgeschlossenen neuen Konzessionsvertrag, der einzelne Bestimmungen der Verträge von 1854 und 1856 im Sinne des Schiedsspruches abänderte. Es darf hinzugefügt werden, daß Art. 16 Abs. 3 dieses Vertrages vorsah, daß Streitigkeiten aus dem Vertrage den innerstaatlichen Gerichten unterworfen und gemäß den Gesetzen des Landes gelöst werden sollten ${ }^{41}$.

In diesem Fall erwies sich die Methode der quasi-völkerrechtlichen Schiedsgerichtsbarkeit als der einzig mögliche friedliche Weg zur Beilegung dieser Investitionsstreitigkeit. Auf zwischenstaatlicher Ebene wäre eine diplomatische Intervention

36 Der Schiedsspruch erging am 2. September $1930 \mathrm{zu}$ Gunsten der Gesellschaft. Dazu siehe: London Times vom 3. September 1930. Lauterpacht AD 1929/30, S. 4 und S. $426 \mathrm{ff}$.; Nussbaum, The arbitration between the Lena Goldfields and the Soviet Government, in: 36 Cornell L. Q. (1930), S. $32 \mathrm{ff}$

$37 \mathrm{La}$ Pradelle, a. a. O., S. 345 und 348. Uber die Rechtsnatur dieser Akte des Vizekönigs herrschte keine Ubereinstimmung; in der Sachverhaltsdarstellung des Kompromissums wird darauf in folgender Weise hingewiesen: "... Le 20 juillet 1856, intervient un nouvel act, qualifié règlement et décret par le Gouvernement égyptien, règlement conventionnel et contrat par la Compagnie.» Id, S. 360. Durch den Schiedsspruch wurde auch diese Frage im Sinne der Rechtsansicht der Gesellschaft geklärt, da durch die Konzessionserteilung ge e n e it ig e Rechte und Pflichten erzeugt werden, Id, S. 363. Weitere Dokumentation siehe: Parry, A British Digest of International Law, Bd. 2 b, S. $193 \mathrm{ff}$

38 Note vom 6. April 1863, La Pradelle, a. a. O., S. 354.

39 Antwort des Verwaltungsrates der Gesellschaft vom 29. Oktober 1863, Id, S. 365.

40 Id, S. 359.

41 Id, S. 377. 
Frankreichs, dessen Staatsangehörige die Majorität des Aktienkapitals in Händen hatten, ohne scharfe Reaktion Großbritanniens nicht denkbar gewesen. Aus diesen Gründen nahm die französische Regierung von solchen Schritten Abstand. Eine Einigung durch andere friedliche Streitbeilegungsmethoden, wie Verhandlung, Vermittlung und Vergleich wurde zum Teil ergebnislos versucht, zum Teil erschienen diese Wege als ungeeignet, da die Natur des Streites - ähnlich wie vielleicht später im Alabama-Fall - eine endgültige Entscheidung verlangte. Wäre die Streitbeilegung auf diesem Wege nicht erfolgt, so kann mit Sicherheit angenommen werden, daß das Kanalprojekt, das mit der Eröffnung des Kanals am 17. November 1869 beendet wurde, überhaupt in Frage gestellt oder zumindest verzögert worden wäre.

In juristischer Hinsicht möge nicht eingewendet werden, daß es sich in diesem Fall nicht um eine Streitigkeit zwischen einem Staat und einer ausländischen Gesellschaft gehandelt habe, da Ägypten lediglich eine Provinz des Osmanischen Reiches und die Gesellschaft die Staatsangehörigkeit Ägyptens, und somit des Osmanischen Reiches besessen habe. Zum ersten besaß Ägypten zu dieser Zeit de f a c t o eine autonome Rechtsordnung, in deren Rahmen sehr wohl Konzessionsverträge solcher Art geschlossen werden konnten ${ }^{42}$. Zum anderen unterstand die Suezkanal-Gesellschaft zwar formell dem ägyptischen Recht, doch muß sie in Hinblick auf ihre Errichtung, Organisation und Kontrolle des Kapitals ohne Zweifel als ausländische angesehen werden, so daß es sich hier um einen echten Fall einer Streitbeilegung auf quasi-völkerrechtlicher Ebene handelt.

Auf der anderen Seite zeigt sich die Schwäche dieser Streitbeilegungsmethode dann, wenn der Anlagestaat nicht gewillt ist, an der Zusammensetzung des Schiedsgerichtes mitzuwirken oder den erlassenen Schiedsspruch zu erfüllen, wie der in der Literatur bisher unbeachtet gebliebene Fall der Betriebsgesellschaft der Orientalischen Eisenbahnen v. Türkei beweist:

Durch Vertrag zwischen der türkischen Regierung als Eigentümerin und der französischen Aktiengesellschaft "Compagnie générale pour l'exploitation des chemins de fer de la Turquie d'Europe" vom 18. Mai $1872^{43}$ wurde letzterer der Betrieb der Eisenbahnlinien der europäischen Türkei ${ }^{44}$ gegen einen jährlichen Pachtzins von $8000 \mathrm{fcs} / \mathrm{km}$ übertragen, wobei sich die Türkei ihrerseits verpflichtete, die Herstellung der nötigen Zufahrtsstraßen zu den Stationen und den Ausbau der Hafenanlagen von Saloniki, Dedeagatsch und Varna vorzunehmen ${ }^{45}$. 1879 wurde diese Gesellschaft bei gleichbleibenden Rechten und Pflichten in eine solche österreichischen Rechtes umgewandelt und als „Betriebsgesellschaft der Orientalischen Eisenbahnen" mit dem Sitz in Wien am 13. Januar 1880 in das Handelsregister Wien eingetragen ${ }^{46}$. Am 22. Dezember 1885 wurde ein weiterer Vertrag zwischen der nunmehr österreichischen Gesellschaft als Rechtsnachfolgerin der „Compagnie générale" und der türkischen Regierung abgeschlossen, der u. a. eine Schiedsklausel enthielt ${ }^{47}$. In der Folge kam es zu Streitigkeiten rechtlicher Natur zwischen der Türkei und der Gesellschaft, da erstere eine Reihe von vertraglich stipulierten Verpflichtungen, so den Ausbau der Hafenanlagen und Straßen, nicht erfüllte ${ }^{48}$.

\footnotetext{
42 So auch La Pradelle und die dort zitierte Literatur, a. a. O., S. 376. Die formelle Emanzipation aus dem osmanischen Reich erfolgte wenig später durch Firman des Sultans vom 8. Juni 1873.

43 Akten des Haus-, Hof- und Staatsarchivs Wien, F 33. 4/1.

$44 \mathrm{Im}$ einzelnen die Linien Konstantinopel-Adrianopel-Tirnowa und Belowa; ferner Saloniki-UskübMitrowitza-Zibeftsche (Art. 1).

45 Art. 12.

46 Compass, Finanzielles Jahrbuch für Osterreich-Ungarn 1903, S. 2061

47 24. Ordentliche Generalversamlung vom 31. Mai 1904, Bericht des Verwaltungsrates, S. 5.

48 Compass 1904, S. 1125.
} 
Das Drängen der Gesellschaft auf Einsetzung des Schiedsgerichts blieb unbeachtet, so daß sich diese an die österreichisch-ungarische Regierung um Unterstützung wandte. Auch zwischenstaatliche Bemühungen, die 1896 ihren Anfang nahmen, blieben vorerst erfolglos, da die Türkei die Angelegenheit weiter hinauszuzögern verstand ${ }^{49}$. Schließlich wurde am 17. Januar 1903 das Kompromissum zwischen der Türkei, vertreten durch den Minister für öffentliche Arbeiten, Zihni Pascha, und der Gesellschaft, vertreten durch den Direktor Ulrich Groß, unterzeichnet. In Hinblick auf die Zusammensetzung des Gerichts enthielt der Schiedsvergleich die Bestimmung, daß je zwei Schiedsrichter von der türkischen und von der österreichischen Regierung ernannt werden sollten ${ }^{50}$. Das Verfahren wurde in einen schriftlichen und einen mündlichen Teil gegliedert, wobei das Gericht eine eigene Verfahrensordnung bestimmen konnte ${ }^{51}$. Entscheidungen werden mit Stimmenmehrheit gefällt ${ }^{52}$, bei Stimmengleichheit sollte ein „Sur-Arbitre“ gewählt werden ${ }^{53}$.

Das Schiedsgericht trat am 28. September 1903 in Konstantinopel zusammen und tagte bis 2. Dezember. Der Antrag der türkischen Regierung auf Aufhebung der Konzessionsverträge von 1872 und 1885 wurde einhellig abgewiesen, den Forderungen der Gesellschaft zum Teil stattgegeben. Über die Hauptfrage, nämlich der Entschädigung für die Nichtausführung des Ausbaues der Häfen und für nichtausgeführte Straßenarbeiten konnte keine Mehrheitsentscheidung erzielt werden, so daß eine Entscheidung darüber einem Oberrichter im Sinne Art. 9 des Kompromissums übertragen werden sollte ${ }^{54}$.

Damit wurde die Entscheidung über die eigentliche Streitfrage abermals hinausgezögert; erst vier Jahre später fand sich die türkische Regierung bereit, im Einvernehmen mit der Gesellschaft den deutschen Kaiser zu ersuchen, die Ernennung einer geeigneten Persönlichkeit als Oberschiedsrichter vorzunehmen ${ }^{55}$. Die Wahl fiel auf den ehemaligen spanischen Ministerpräsidenten S. Moret y Prendergast, welcher am 17. November 1907 ausschließlich zugunsten der Gesellschaft entschied.

Der Schiedsspruch wurde von der türkischen Regierung jedoch vorerst nicht erfüllt, so daß der Verfasser des Berichtes des Verwaltungsrates der Gesellschaft vom 23. Juni 1908 feststellen mußte: „... wir hoffen, daß das Billigkeitsgefühl der kaiserlich ottomanischen Regierung und die Unterstützung der österreichischungarischen Diplomatie zu einer endgültigen Erledigung dieser Angelegenheit führen werde." 56

Durch Vertrag zwischen der türkischen Regierung und der Gesellschaft vom 15. Juni 1909 wurde dieser Fall abgeschlossen: die türkische Regierung verpflichtete sich darin zur Entrichtung einer Entschädigungssumme von 21,5 Millionen Goldfrancs, doch mußte die Gesellschaft innerhalb von zehn Monaten in eine solche türkischen Rechtes mit dem Sitz in Konstantinopel umgewandelt werden ${ }^{57}$. Die Umwandlung wurde unter Beibehaltung der finanziellen und organisatorischen Einrichtungen der Gesellschaft in der vereinbarten Zeit vollzogen.

\footnotetext{
49 Note betreffend den gegenwärtigen Stand der Reclamationen gegen die türkische Regierung, Wien, 27. September 1901, Akten des Haus-, Hof- und Staatsarchivs Wien, 19 Türkei 8.

50 Art. 1. Die Türkei ernannte den Marineminister Mahmud Dschellaleddin Pascha und den Rechtsberater der Regierung Gabriel Noradounghian, während Österreich-Ungarn den Präsidenten des k. und k. Konsularappelationsgerichtes in Konstantinopel MinRat. Stephan v. Kvassay sowie den ehemaligen französischen Justizminister Senator Victor Milliard zu Schiedsrichtern bestellte. Bericht des Verwaltungsrates, 31. Mai 1904, S. 5.

51 Art. 2.

52 Art. 5.

53 Art. 9 .

54 Bericht des Verwaltungsrates, S. 6.

55 Bericht des Verwaltungsrates, 23. Juni 1908, S. 4.

56 Id, S. 5.

57 Akten des k. und k. Ministeriums des Innern, 15/10, Nr. 43288-09.
} 
Von der Seite des materiellen Rechts stellt dieses Beispiel einen beachtenswerten Präzedenzfall in Hinblick auf die Unzulässigkeit der einseitigen Aufhebung von Konzessionsverträgen dar, doch zeigt es dabei auch deutlich die Mängel der gegenständlichen Streitbeilegungsmethode, wenn es an einer diesbezüglichen Bereitschaft des Anlagestaates fehlt. In einem solchen Fall muß der Heimatstaat des Investors tätig werden, wodurch der Streit auf die internationale Ebene gebracht wird.

Die Behandlung weiterer Fälle der Streitbeilegung von Investitionsstreitigkeiten durch quasi-völkerrechtliche Schiedsinstanzen würde in Anbetracht der bereits erfolgten weitgehenden wissenschaftlichen Durchdringung 58 den Rahmen dieser Untersuchung sprengen und für die Ergebnisse, die wie folgt zusammengefaßt werden können, keine wesentliche Änderung bringen.

Unter dem Aspekt der prozessualen Stellung der Einzelperson lassen sich abschließend die traditionellen Methoden zur Beilegung von Investitionsstreitigkeiten in drei Gruppen gliedern ${ }^{50}$ :

a) Die Errichtung einer Schiedsinstanz zwischen dem Heimatstaat des Investors und dem Anlagestaat, wobei dem Heimatstaat die ausschließliche Kontrolle über den Anspruch des durch Akte des fremden Staates geschädigten Individuums vorbehalten bleibt. Prozeßpartei sind daher ausschließlich die beteiligten $S \mathrm{t}$ a a $\mathrm{t}$ e $\mathrm{n}$.

b) Gleichfalls die Errichtung einer Schiedsinstanz zwischen dem Heimatstaat und dem fremden Staat, zu welcher jedoch dem Individuum direkter Zugang gewährt wird und ihm aus dem Schiedsspruch ein unmittelbarer Rechtsanspruch gegen den fremden Staat erwächst. Prozeßpartei sind gleichfalls beide Staaten, doch wird sozusagen ein Teil der Parteifähigkeit an das geschädigte Individuum abgetreten.

c) Die Errichtung einer Schiedsinstanz zwischen dem Individuum (Gesellschaft) und dem Staat auf quasi-völkerrechtlicher Ebene. Hier wird in Hinblick auf die Gestaltung des das Schiedsgericht konstituierenden Instruments die Einzelperson gleichberechtigter Vertragspartner des Anlagestaates und tritt daher im Verfahren dem fremden Staat ebenfalls gleichberechtigt gegenüber. Der Heimatstaat des verletzten Individuums ist rechtlich in keiner Weise beteiligt, Prozeßpartei sind ausschließlich der fremde $S \mathrm{t}$ a a $\mathrm{t}$ und die $\mathrm{E}$ in $\mathrm{z}$ el perso $\mathrm{n}$.

Es darf aber betont werden, daß die Fälle unter lit. b) und c) im traditionellen System der internationalen Gerichtsbarkeit durchwegs Ausnahmen darstellten, die aber nichtsdestoweniger Beweis dafür bieten, daß dem Individuum im beschränkten Bereiche eine internationale Partei- und Prozeßfähigkeit zuerkannt wurde. Diese Erscheinung erfuhr in jüngster Vergangenheit durch den Abschluß der „Weltbankkonvention zur Beilegung von Investitionsstreitigkeiten zwischen Staaten und Angehörigen fremder Staaten " eine vielversprechende Erweiterung, welche Gegenstand der folgenden Darstellung sein wird.

$58 \mathrm{Vgl}$. dazu die auf S. 266 angeführte Literatur. Die bekanntesten der hier nicht näher angeführten Fälle sind: Administration of Posts and Telegraphs of the Republic of Czechoslovakia v. Radio Corporation of America (Stuyt, Nr. 385); China v. Radio Corporation of Amerika (Stuyt, Nr. 386), Lena Goldfields Ltd. v. USSR (Stuyt, Nr. 370), und die auf S. 268 angeführte Literatur; Petroleum Development Ltd. v. Sheik of Abu Dhabi (ILR 1951, S. 144); Petroleum Development (Qatar) Ltd. v. Ruler of Qatar (ILR 1951, S. $161 \mathrm{ff}$.); Ruler of Qatar v. International Marine Oil Co. Ltd. (ILR 1953, S. 534 ff.); Saudi Arabia v. Arabian American Oil Co. (ILR 1963, Bd. 27, S. $117 \mathrm{ff}$.); Sapphire v. National Iranian Oil Company (P. F. Lalive, siehe oben S. 267, Fußnote 29).

59 Ausgenommen von dieser Betrachtung sind solche Schiedsinstanzen, die im Rahmen privater internationaler Organisationen, wie z. B. der Internationalen Handelskammer, eingerichtet sind. Zur letzteren siehe Eisemann-Kreuz, Die internationale Handelskammer, Zeitschrift f. a. ö. R. u. VR 14 (1951); Eisemann, Arbitration under the I. C. C. Rules, in: 15 ICLQ (1966), S. $726 \mathrm{ff}$. 


\section{Die Institutionalisierung der Schiedsgerichtsbarkeit zwischen Staaten und Einzelpersonen durch die Weltbankkonvention vom 18. März 1965}

\section{Der historische Hintergrund der Konvention}

Wie im vorhergehenden Abschnitt ausgeführt wurde, lag die Schwäche der traditionellen Streitbeilegungsmethode von Investitionsstreitigkeiten hauptsächlich darin, daß in nahezu allen Fällen der Heimatstaat des Investors in irgendeiner Form tätig werden mußte; zwar zeigt das System der Schiedsklauseln in Konzessionsverträgen den Versuch der Ausschaltung des Heimatstaates, doch auch die Wirksamkeit solcher Klauseln hängt letzten Endes vom guten Willen des Anlagestaates ab, da in der Regel der Abschluß eines Kompromissums, in welchem nähere Bestimmungen in Hinblick auf die Zusammensetzung des Schiedsgerichtes, der dem Gericht vorzulegenden Fragen usw. enthalten sind, nach Entstehung des Streitfalles notwendig ist $^{60}$. Eine weitere Schwäche der tradionellen Ad-hoc-Schiedsgerichtsbarkeit lag auch in dem nicht zu unterschätzenden Aufwand verwaltungstechnischer Natur, der die Errichtung eines Schiedsgerichts nur bei Vorliegen eines hohen Streitwertes finanziell rechtfertigte.

Auf der anderen Seite ließ die wachsende internationale Investitionstätigkeit im Anschluß an den zweiten Weltkrieg das Bedürfnis nach verstärktem Schutz ${ }^{61}$ von privaten Auslandsinvestitionen entstehen. Neben bilateralen Investitionsschutzverträgen ${ }^{62}$ und gleichgerichteten Bemühungen nach multilateralem Schutz ${ }^{63}$ erschien ein wirksames System der Schiedsgerichtsbarkeit auf freiwilliger Basis hierzu als geeignetes Mittel, wobei in Anbetracht der genannten Mängel der traditionellen Streitbeilegungsmethoden die Errichtung einer ständigen, dem Individuum unmittelbar zugänglichen Rechtsschutzinstanz im Mittelpunkt der Überlegungen stand.

Zunächst wurde versucht, die Zuständigkeit einer bereits bestehenden Institution, nämlich des Ständigen Haager Schiedshofes, in diesem Sinne zu erweitern, wobei Art. 47 des 1. Haager Abkommens von 1907 die rechtliche Grundlage bieten sollte ${ }^{64}$. Am 26. März 1962 wurden die vom Büro ausgearbeiteten „Rules of Arbitration and Conciliation of International Disputes between two Parties of which only one is a State" vom Ständigen Verwaltungsrat des Schiedshofes angenommen und den Vertragsstaaten zugeleitet ${ }^{65}$.

Parallel zu diesen Bemühungen des Ständigen Haager Schiedshofes ging der im Rahmen der Weltbank entwickelte Plan zur Errichtung einer neuen internationalen Rechtssprechungsinstanz, die Einzelpersonen in Streitigkeiten über Kapitalanlagen

$60 \mathrm{Vgl}$. oben S. 270.

61 Hierzu vor allem Seidl-Hohenveldern, Investitionen in Entwicklungsländern und das Völkerrecht mit einer Bibliographie über Staatseingriffe in ausländisches Privateigentum (1963).

62 Dazu Berger, Vermögensschutz im Ausland durch Investitionsförderungsverträge, in: Außenwirtschaftsdienst des Betriebsberaters 1965, S. $1 \mathrm{ff}$.

63 Allgemein darüber siehe Nwogugu, The Legal Problems of Foreign Investment in Developing Countries, Manchester University Press (1965), S. $135 \mathrm{ff}$. Vgl. in diesem Zusammenhang insbesondere den OECDEntwurf einer Konvention zum Schutze von Kapitalanlagen, Draft Convention on the Protection of Foreign Property, OECD Paris (1967)

64 Vgl. "Circular Note of the Secretary-General of the Permanent Court of Arbitration of 3 March, 1960“, in: 54 AJIL (1960), S. $933 \mathrm{ff}$. Art. 47 des Abkommens zur friedlichen Erledigung internationaler Streitfälle vom 18. Oktober 1907 lautet: "Das Büro ist ermächtigt, sein Geschäftslokal und seine Geschäftseinrichtung den Vertragsmächten für die Tätigkeit eines jeden besonderen Schiedsgerichts zur Verfügung zu stellen. Die Schiedsgerichtsbarkeit des Ständigen Schiedshofs kann unter den durch die allgemeinen Anordnungen festgesetzten Bedingungen auf Streitigkeiten zwischen anderen Mächten als Vertragsmächten erstreckt werden, wenn die Parteien übereingekommen sind, dieses Schiedsgericht anzurufen. “ mächten erstreckt werden, wenn die Parteien übereingekomm
Berber, Völkerrecht (Dokumentensammlung), Bd. II, S. 1691.

65 Abgedruckt in 57 AJIL (1963), S. $500 \mathrm{ff}$; ; siehe auch G. Guyomar, Le règlement de la Cour permanente d'arbitrage relatif aux conflits internationaux entre deux parties dont une seule est un Etat, in Annuaire Francais de D. I. (1962), S. $377 \mathrm{ff}$. 
mit fremden Staaten unmittelbar zugänglich sein sollte. Die entpolitisierte Atmosphäre und die notorische Unparteilichkeit versetzte die Weltbank wie kein anderes Forum in die Lage, auch auf die Mitarbeit des Großteils der neuen Staaten bauen zu können, die den bestehenden internationalen Rechtssprechungsinstanzen eher ablehnend gegenüberstehen. Sowohl von privaten Investoren als auch von Regierungen der Mitgliedstaaten wurden in den fünfziger Jahren die Dienste der Bank zur Beilegung von Investitionsstreitigkeiten mit Erfolg in Anspruch genommen $^{66}$; das ghanaische Investitionsförderungsgesetz (Ghana Capital Investments Act) vom 19. April $1963^{67}$ übertrug der Weltbank subsidiär die Rolle eines Schiedsrichter für den Fall, daß es bei (ausnahmsweisen) Enteignungen zwischen dem ausländischen Investor und dem Staat zu keiner Einigung über die Höhe der Entschädigung sowie über einen $\mathrm{zu}$ ernennenden Schiedsrichter kommen sollte. Dieses der Bank sowohl von kapitalimportierenden wie kapitalexportierenden Staaten entgegengebrachte Vertrauen war somit der Grundstein für die Schaffung einer im Rahmen der Bank institutionalisierten internationalen Rechtssprechungsinstanz, deren Vorteile sowohl für die Entwicklungsländer selbst als auch für den privaten Investor evident sind $^{\mathbf{6 8}}$.

Die Arbeit an einer diesbezüglichen Konvention nahm auf der 17. Jahresversammlung des Rats der Gouverneure ihren Anfang, auf welcher eine Resolution ${ }^{69}$, durch die das Direktorium zur Prüfung der damit zusammenhängenden Fragen aufgefordert wurde, einstimmige Annahme fand. Im Laufe des Jahres 1963 wurde auf der Grundlage von einzelnen von Beamten der Bank hergestellten Arbeitsentwürfen innerhalb der Bank die Problematik erörtert und sodann vom Direktorium die Abhaltung von beratenden Versammlungen zur weiteren Diskussion beschlossen, welche nach regionalen Gesichtspunkten organisiert und zu welchen Experten der Regierungen der Mitgliedstaaten eingeladen wurden. Diese in Addis Abbeba (16.-20. Dezember 1963), Santiago de Chile (3.-7. Februar 1964), Genf (17.-21. Februar) und Bangkok (27. April-1. Mai 1964) abgehaltenen Regionalversammlungen ${ }^{70}$, an denen Vertreter von 86 Mitgliedstaaten teilnahmen, boten der Bank nicht nur die Möglichkeit zur Feststellung der Haltung der Mitgliedstaaten zu diesem Projekt, sondern gestatteten auch die Sammlung wertvoller Informationen über die verschiedenen Rechtsstandpunkte der Entwicklungsländer gegenüber ausländischen Privatinvestitionen im allgemeinen.

Auf Grund der positiven Ergebnisse der Regionalversammlungen unterbreitete das Direktorium dem Rat der Gouverneure einen günstigen Bericht, der auf der in Tokio abgehaltenen Jahresversammlung die Basis für eine weitere Resolution bildete, durch welche das Direktorium zur Formulierung einer Konvention (to formulate a convention) aufgefordert wurde ${ }^{71}$, die die Schaffung von Schieds- und Vergleichseinrichtungen zur Beilegung von Investitionsstreitigkeiten zwischen Staaten und Staatsangehörigen anderer Vertragsstaaten auf freiwilliger Basis zum Gegenstand haben sollte ${ }^{72}$.

\footnotetext{
66 So die Darbietung guter Dienste seitens der Bank im Streitfall zwischen der Suezkanal-Gesellschaft und Ägypten im Jahre 1956; ebenso die Vermittlertätigkeit des Weltbankpräsidenten Mr. E. Black im Falle der City-of-Tokyo-Anleihe zwischen Frankreich und Japan 1958; darüber siehe: Policies on the Operation of the World Bank, IFC and IDA, amended to June 30, 1963.

67 Act No. 172 section 8. Vgl. Nwogugu, a. a. O., S. 34 und 56.

68 Ansprache des Präsidenten Eugen R. Black am 19. September 1961 auf der in Wien abgehaltenen 16. Jahresversammlung des Rats der Gouverneure. Roulet, a. a. O., 125, Sassoon, Convention on the Settlement of Investment Disputes, Journal of Business Law 1965, S. 335.

69 Resolution Nr. 174 vom 18. September 1962. Siehe $\$ 6$ des Reports.

$70 § 7$ des Berichts. Roulet, a. a. O., S. 126.

71 Resolution Nr. 214 vom 10. September 1964. Abgedruckt in $\$ 1$ des Berichts.

$72 \mathrm{Vgl}$. dazu Absatz 4 der Präambel der Konvention.
} 
Statt eine allgemeine Staatenkonferenz einzuberufen, lud das Direktorium ${ }^{73}$ die Mitgliedstaaten der Weltbank zur Entsendung von Experten ein, welche in ihrer Gesamtheit ein juristisches Komitee (Legal Committee) ${ }^{74}$ zur Beratung des Direktoriums bildeten ${ }^{75}$. Auf diese Weise wurde den Schwierigkeiten einer Staatenkonferenz ausgewichen und gleichzeitig den Mitgliedstaaten Gelegenheit zur Mitarbeit an der Konvention geboten, wodurch die Voraussetzung zur deren möglichst universellen Annahme geschaffen wurde. Das Komitee, an dem 61 Staaten vertreten waren, tagte in Washington vom 23. November bis 11. Dezember 1964 und konnte in dieser verhältnismäßig kurzen Zeit den gesamten Text der Konvention redigieren, der zu Beginn des Jahres 1965 dem Direktorium vorgelegt und am 18. März 1965 den Mitgliedstaaten der Bank zur Unterzeichnung und Ratifikation übermittelt wurde ${ }^{76}$. Außer den Mitgliedern der Bank können auch solche Staaten der Konvention beitreten, welche Vertragspartei des Statuts des Internationalen Gerichtshofes sind u n d vom Verwaltungsrat mit Zweidrittelmehrheit seiner Mitglieder zur Unterzeichnung eingeladen wurden ${ }^{77}$.

Die Konvention trat einen Monat nach Hinterlegung der zwanzigsten Ratifikationsurkunde ${ }^{78}$ am 14. Oktober 1966 in Kraft. Bis zum gegenwärtigen Zeitpunkt wurde sie von 57 Staaten unterzeichnet, von welchen 38 bereits ratifiziert haben ${ }^{79}$.

\section{Das Internationale Zentrum zur Beilegung von Investitionsstreitigkeiten}

\section{a. Rechtsstellung und Organisationsstruktur}

Die auf den Regionalversammlungen gesammelten Erfahrungen ließen das Projekt eines obligatorischen Schiedssystems als unreell erscheinen. Nicht nur die Entwicklungsländer, sondern auch eine Reihe von Industriestaaten befürworteten lediglich die Schaffung einer Rechtssprechungs- und Vergleichsinstanz, die den Parteien auf deren Wunsch zur Verfügung stand. Wie im Falle der Annahme des Statuts des Internationalen Gerichtshofs noch keine obligatorische Gerichtsbarkeit begründet wird, sollte allein durch die Ratifizierung der geplanten Konvention den Vertragstaaten noch keine Verpflichtung zur Unterwerfung unter ein Vergleichs- oder Schiedsverfahren entstehen ${ }^{80}$. Auf der anderen Seite sollte jedoch die geschaffene Institution in der Lage sein, sobald einmal übereinstimmende Unterwerfungserklärungen abgegeben wurden, durch eine anpassungsfähige Struktur den Besonderheiten von Investitionsstreitigkeiten Rechnung tragen zu können und eine rasche und wirkungsvolle Durchführung des Verfahrens zu gewährleisten ${ }^{81}$. Die Verwirklichung der gesteclsten Ziele stellte das nach dem Vorbild des Ständigen Haager Schiedshofes geschaffene „Internationale Zentrum zur Beilegung von Investitionsstreitigkeiten“ (im folgenden "Zentrum“ genannt) dar.

\footnotetext{
73 Roulet, a. a. O., S. 127.

$74 \$ 8$ des Berichts.

75 Ausführlich über das Verfahren im Komitee siehe Roulet, a. a. O., S. 127-129.

76 Wie im Falle der Internationalen Finanz-Corporation und der Internationalen Entwicklungsorganisation wurde der Gründungsvertrag der neuen Organisation im Rahmen der Bank ausgearbeitet, dem die Mitgliedstaaten später "beitraten“.

77 Art. 67. So wurde "die Schweiz auf der Eröffnungssitzung des Verwaltungsrates am 2 . Februar 1967 zur Unterzeichnung eingeladen. ICSID, First Annual Report 1966/67, S. 3.

78 Art. 68

79 Das Manuskript wurde mit 30. April 1968 abgeschlossen. Eine Liste jener Staaten, die bis zu diesem Zeitpunkt unterzeichnet und ratifiziert haben, ist dem Kapitel über die Haltung der neuen Staaten zur Konvention beigegeben. Siehe unten S. 297.

80 Absatz 7 der Präambel der Konvention.

81 Roulet, a. a. O., S. 130.
} 
Das Zentrum ${ }^{82}$ selbst ist keine - wie vielleicht angenommen werden könnte Vergleichs- oder schiedsgerichtliche Instanz, sondern stellt lediglich den Parteien solche Einrichtungen zur Verfügung83, und dessen Tätigkeit erstreckt sich ausschließlich auf internationale Verwaltungsaufgaben. $\mathrm{Da}$ es somit keinerlei Rechtssprechungsbefugnis besitzt ${ }^{84}$, wurde aus diesen Gründen der Ausdruck „Gerichtshof" oder "Schiedsgericht" hierfür vermieden und jener Kritik vorgebeugt, welcher der Ständige Haager Schiedshof seit seiner Gründung vor beinahe 70 Jahren ausgesetzt ist. Durch den Terminus „Zentrum“ sollte somit die vorwiegend verwaltende Tätigkeit zum Ausdruck gegbracht werden ${ }^{85}$.

Begreift man mit Zemanek ${ }^{86}$ eine internationale Organisation als eine "durchKollektivvertrag geschaffene, autonom organisierte völkerrechtliche Verbindung von Staaten zur Verfolgung gemeinsamer Interessen der Mitgliedergemeinschaft", so ist das Zentrum seiner Rechtsnatur nach als eine solche anzusehen, doch weist es zwei Besonderheiten auf: zum ersten zählen zu den Parteien des Gründungsvertrages nicht nur Staaten, sondern auch eine andere Internationale Oganisation, nämlich die Weltbank, der im übrigen durch die Konvention die Funktion des Depositars übertragen wurde ${ }^{87}$. Zum zweiten ist zwar das Element der Organautonomie in bezug auf die Mitgliedstaaten vollkommen verwirklicht, doch hat es auf Grund der historischen Verbindung zur Weltbank im Verhältnis zu dieser eine gewisse Einschränkung erfahren, auf die gleich zurückzukommen sein wird88.

Im Gegensatz zu der Mehrzahl der bestehenden internationalen Organisationen erkennt der Gründungsvertrag89 dem Zentrum ausdrücklich eine völkerrechtliche Rechtspersönlichkeit zu und räumt ihm in privatrechtlicher Hinsicht die Fähigkeit zum Abschluß von Verträgen, zum Erwerb und zur Veräußerung von beweglichem und unbeweglichem Vermögen und das Recht zur Inanspruchnahme von innerstaatlichen Gerichten ein. Sitz des Zentrums ist der Sitz der Weltbank, doch kann ersterer durch Beschluß des Verwaltungsrates des Zentrum „an einen anderen Ort“ verlegt werden; eine solche, unter Umständen aus politischen Gründen zu rechtfergende Sitzverlegung hätte allerdings zur Folge, daß damit die durch die Weltbank getragene (vorläufige) Finanzierung des Zentrums sowie die kostenlose Úberlassung von Verwaltungsräumen eingestellt werden würde ${ }^{90}$. Schieds- und Vergleichsverfahren finden am Sitz des Zentrums statt ${ }^{91}$, doch können die Parteien einen anderen Ort vereinbaren, wie z. B. den Sitz des Ständigen Schiedshofes ${ }^{92}$.

Zwischen der Weltbank und dem Zentrum besteht nicht nur eine weitreichende Verbindung in finanzieller Hinsicht, sondern auch eine solche personell-organisatorischer Natur: der Präsident der Weltbank ist e $\mathrm{x}$ of f i c i o zugleich Vorsitzender des Verwaltungsrates ${ }^{\mathbf{3}}$ und erhält damit weitgehende Befugnisse in Hinblick auf die Gestaltung des Organisationszweckes. So besitzt er ein Vorschlagsrecht zur

82 Engl.: „International Centre for Settlement of Investment Disputes“; franz.: „Centre International pour le Règlement des Différends relatifs aux Investissements". Im Deutschen wurde der Ausdruck "Zentrale" vorgeschlagen, siehe Berger, a. a. O., S. 434.

83 Art. 1 Abs. 2.

84 Die einzige Ausnahme ist vielleicht die Funktion des Generalsekretärs nach Art. 28 Abs. 3. Dazu unten S. 278.

85 Roulet, a. a. O., S. 131, Fußnote 29.

86 "Das Vertragsrecht der internationalen Organisationen“, Wien 1957, S. 17.

87 Art. 73. Vgl. die Aufgaben des Depositars nach Art. 74 und 75.

88 Siehe unten S. 277.

89 Art. 18. 90 S 17 des Berichtes des Direktoriums der Weltbank: Im Sinne des Beschlusses des Direktoriums wurde am
13. Februar 1967 (mit auf 14. Oktober 1966 rückwirkender Kraft) das „Memorandum of Administrative Arrangements agreed between the International Bank for Reconstruction and Development and the International Centre for Settlement of Investment Disputes “ unterzeichnet, welches das Zentrum zu einer Rückzahlung der empfangenen Leistungen an die Bank allerdings nur bis zur Höhe der von den Parteien eingehobenen Gebühren verpflichtet. ICSID, Annual Report 1966/67, S. 5.

91 Art. 62.

92 Art. 63.

93 Art. 5. 
Bestellung des Generalsekretärs ${ }^{94}$, hat Anteil an der Zusammenstellung der Schiedsrichter- und Vermittlerliste ${ }^{95}$ und kann bei Weigerung einer Partei, den Vermittler oder Schiedsrichter $\mathrm{zu}$ ernennen, diese Entscheidung selbst vornehmen ${ }^{96}$. Ebenso erfüllt der Vorsitzende des Verwaltungsrates im Rahmen des Aufhebungsverfahrens von Schiedssprüchen wichtige Funktionen bei der Zusammensetzung des durch Art. 52 vorgesehenen Ad-hoc-Ausschusses. Im Verwaltungsrat besitzt der Vorsitzende kein Stimmrecht und übt seine Tätigkeit ehrenamtlich aus ${ }^{97}$.

Die historische Patenschaft der Weltbank hat durch diese faktische und personellorganisatorische Verbindung des Zentrums mit der Bank ihren Niederschlag gefunden. Es darf aber betont werden, daß die dadurch bewirkte Abhängigkeit sich ausschließlich auf den Bereich der Verwaltung beschränkt und somit ein Eingreifen der Weltbank in den Streitschlichtungsmechanismus der durch das Zentrum geschaffenen Institutionen in jeder wie immer gearteten Weise ausgeschlossen ist.

Im Bereiche der Vertragsstaaten genießt das Zentrum die für die Wahrnehmung seiner Aufgaben im einzelnen festgelegten Immunitäten ${ }^{98}$, die sich u. a. auf die Ausnahme von der Gerichtsbarkeit ${ }^{99}$, auf Steuer- und Zollbefreiungen ${ }^{100}$ und auf den Schutz der Archive erstrecken ${ }^{101}$. Persönliche Immunität in Hinblick auf Amtshandlungen genießen u. a. der Vorsitzende und die Mitglieder des Verwaltungsrates, Schiedsrichter, Vermittler, Beamte des Sekretariats sowie weiter in Art. 21 und 22 genannte Personen. In allen Fällen kann jedoch das Zentrum auf diese Vorrechte verzichten ${ }^{102}$.

Die Organisationsstruktur des Zentrums ist durch Einfachheit und Wirtschaftlichkeit in Hinblick auf die Erfüllung der übertragenen Funktionen gekennzeichnet ${ }^{\mathbf{1 0 3}}$. Es bestehen nur zwei Organe, der V e r w a l t u n g s a t (Administrative Council) als leitendes Organ, in welchem alle Mitglieder vertreten sind ${ }^{104}$, und das S e k r e t a r i a t (Secretariat), das sich aus dem Generalsekretär, dessen Stellvertretern und dem notwendigen Personal zusammensetzt ${ }^{105}$. In die Kompetenz des Verwaltungsrates, der einmal jährlich zusammentritt ${ }^{105 a}$, fallen dieBestellung des Generalsekretärs und der stellvertretenden Generalsekretäre durch Wahl ${ }^{106}$, die Beschlußfassung über die Verwaltungs- und Finanzordnung der Organisation, über die Verfahrensordnung für die Einleitung von Vergleichs- und Schiedsverfahren sowie über die (getrennten) Verfahrensordnungen für das Vergleichs- und für das Schiedsverfahren ${ }^{107}$. Auf der Eröffnungstagung des Verwaltungsrates am 2. Februar 1967 wurde Mr. A. Broches zum Generalsekretär des Zentrums bis 30. September 1968

94 Art. 10 Abs. 1.

95 Art. 13 Abs. 2. Siehe dazu unten S. 289.

96 In Hinblick auf weitere Befugnisse siehe Art. 7 Abs. 1 und Abs. 4.

97 Art. 5 und Art. 8.

98 Art. 20-24.

99 Art. 20.

100 Art. 24

101 Art. 23 Abs. 1

102 Art. 20, Art. 21 lit. a und Art. 22. Im einzelnen führt regulation 32 der am 2 . Februar 1967 vom Verwaltungsrat angenommenen Verwaltungs- und Finanzordnung (Administrative and Financial Regulations) dazu näher aus, daß der Verwaltungsrat als leitendes Organ für die Aufhebung der Immunität aller durch die Konvention priviligierter Personen sowie der Organisation selbst zuständig ist; Immunität aller durch die Konvention priviligierter Personen sowie der Organisation selbst zuständig ist;
der Vorsitzende des Verwaltungsrates kann auf die Immunität des Generalsekretärs oder seiner Stellvertreter, auf die der Mitglieder einer Kommission, eines Gerichts oder Ausschusses (vgl. Art. 52 Abs. 3) sowie auf die der in Art. 22 genannten Personen (i. s. Parteien, Rechtsbeistände usw.) verzichten, letzteres jedoch nur, wenn durch das Streitschlichtungsorgan solches empfohlen wird; der Generalsekretär ist schließlich zuständig für den Immunitätsverzicht für die Organisation und ihrer Beamten. ICSID/4, S. 22.

103818 des Berichts.

104 Art. 4.

105 Art. 9.

105a Art. 7. Aus Zweckmäßigkeitsgründen wird die Jahresversammlung mit der Jahrestagung des Gouverneursrats der Weltbank verbunden werden, wie es der vorbereitende Entwurf vorsah. Vgl. Amadio, a. a. O., S. 75.

106 Art. 10.

107 Art. 6 Abs. 1 lit a-c. Über die weiteren Funktionen des Verwaltungsrates siehe Art. 6 Abs. 1 e-g, Abs. 2 und die Generalklausel des Absatzes 3. 
gewählt ${ }^{108}$ und vorläufige Verfahrensordnungen im genannten Sinne durch Resolution angenommen ${ }^{109}$. In gleicher Weise wurde die durch Art. 6 Abs. 1 lit. d vorgesehene Verwaltungsvereinbarung mit der Weltbank genehmigt.

Zum Unterschied vom Abstimmungsverfahren im Gouverneursrat der Weltbank, in dem die Anzahl der einem Mitgliedstaat zur Verfügung stehenden Stimmen von den Anteilen dieses Staates am Grundkapital der Bank abhängig ist, besitzt im Verwaltungsrat des Zentrums jedes Mitglied nur eine Stimme; der Vorsitzende ist, wie oben erwähnt, vom Stimmrecht ausgeschlossen; durch diese Bestimmung soll seinem, ihm auch als Präsidenten der Weltbank zukommenden unparteiischen Charakter besondere Betonung beigelegt werden ${ }^{110}$.

Das Sekretariat ist die ständige Verwaltungseinrichtung der Organisation, an deren Spitze der Generalsekretär als oberster Beamter steht. Er wird auf sechs Jahre gewählt, wobei Wiederwahl zulässig ist ${ }^{111}$. $\mathrm{Zu}$ seinen Hauptaufgaben zählt die verwaltungstechnische Leitung der Organisation ${ }^{112}$, deren rechtlicher Vertreter er im Innen- und Außenverhältnis ist. Er ist befugt, die auf Grund der Konvention erlassenen Schiedssprüche zu beurkunden und Abschriften davon zu beglaubigen ${ }^{113}$. Er übt ferner die Funktion eines Greffier aus mit der Befugnis, die von den Parteien gestellten Anträge auf Einleitung eines Schieds- oder Vergleichsverfahrens $\mathrm{zu}$ registieren. In diesem Zusammenhang ist seine Tätigkeit quasi-rechtssprechender Natur ${ }^{114}$, da die Konvention ihn ermächtigt, die Registrierung von Anträgen zu verweigern, wenn er auf Grund der in ihnen gemachten Angaben feststellt, daß die Streitigkeit offensichtlich nicht in die Zuständigkeit des Zentrums fällt115. Bedenken wurden gegen diese Bestimmung geäußert, wobei vor allem vorgebracht wurde ${ }^{116}$, daß eine solche Befugnis mit der Verwaltungsfunktion des Generalsekretärs unvereinbar wäre, daß Schiedsgericht und Vergleichskommission selbst über ihre Zuständigkeit entscheiden könnten ${ }^{117}$ und daß damit der Generalsekretär $\mathrm{a} b$ in it io die Einleitung jedes Verfahrens verhindern könnte, da gegen seine Entscheidung kein Rechtsmittel gegeben sei118. Diese vor allem in den Regionalversammlungen und im Juristenkomitee vorgebrachten Einwendungen übersehen jedoch, daß jedem subjektiven Recht ein Mißbrauch potentiell inherent ist. Weiter verfolgt diese Bestimmung den Zweck, das Vorbringen solcher Anträge zu verhindern, die z. B. gegen Staaten gerichtet sind, die nicht Vertragspartei der Konvention wurden ${ }^{119}$. Gerade hier zeigt sich die Problematik von Individualklagen gegen Staaten, die zwar rechtlich auf das konkrete Verhältnis Einzelperson-Staat vornehmlich beschränkt bleiben, aber politis ch eine Fernwirkung auf das Verhältnis Heimatstaat - belangter Staat notwendigerweise ausüben. Die behauptete quasi-rechtssprechende Befugnis des Generalsekretärs tritt daher gegen die auch zugleich politische Funktion des "screenings" von offensichtlich außerhalb des Zuständgikeitsbereiches des Zentrums gelegenen Anträgen in den Hintergrund. Wohl ist richtig, daß die Konvention kein Rechtsmittel gegen ungerechtfertigte Antragsabweisungen durch den Generalsekretär vorsieht, doch bei

108 AC(IM)/RES/1. Abgedruckt in: ICSID, First Annual Report 1966/67, S. 15.

109 AC(IM)RES/2., id., S. 15. Auf der ersten Jahresversammlung des Verwaltungsrates wurden am 25. September 1967 sodann die endgültigen Verfahrensordnungen angenommen. Doc. ICSID/4. Die Schiedsordnung ist der Dokumentation angeschlossen.

110 Art. 7 Abs. 2. Amadio, a. a. O., S. 79.

111 Art. 10 Abs. 1.

112 Art. 11.

113 Art. 11.

114 Vgl. Roulet, a. a. O., S. 132.

115 Art. 28 Abs. 3 und Art. 36 Abs. 3

116 So auch von Berger, a. a. O., S. 436.

117 Art. 32 Abs. 1 und Art. 41 Ảbs. 1.

118 Vgl. Roulet, a. a. O., S. 132.

119 Vgl. \& 20 des Berichts. 
manifester Rechtsverletzung wäre es durchaus denkbar, daß der Verwaltungsrat als Kreationsorgan des Generalsekretärs diesen wieder seines Amtes entheben oder dessen Beschlüsse aufheben könnte. Die rechtliche Grundlage würde meines Erachtens die Generalklausel des Art. 6 Abs. 3 in Verbindung mit Abs. 1 lit. e bieten ${ }^{120}$. Doch scheint dieses Problem rein theoretischer Natur zu sein, da die für das Zentrum notwendige Gewinnung und Erhaltung des Vertrauens bei Staaten und Investoren vermuten läßt, das der jeweilige Generalsekretär bei Vorliegen geringster Zweifel den Antrag registrieren und die Entscheidung über die Zulässigkeit der Vergleichsbzw. Schiedsinstanz selbst überlassen wird ${ }^{121}$.

Nach dem Vorbild des Systems des Ständigen Haager Schiedshofes führt das Zentrum je ein Verzeichnis von Vermittlern und von Schiedsrichtern ${ }^{122}$. Für jedes Verzeichnis kann jeder Vertragsstaat vier Personen namhaft machen, die auch eine andere als seine Staatsangehörigkeit besitzen können ${ }^{123}$. Der Vorsitzende des Verwaltungsrates hat überdies das Recht, für jedes Verzeichnis zehn Personen namhaft $\mathrm{zu}$ machen, die alle verschiedener Staatsangehörigkeit sein ${ }^{124}$ und die hauptsächlichsten Rechtssysteme der Welt und die Hauptformen wirtschaftlicher Betätigung repräsentieren sollen ${ }^{125}$. Diese Bestimmung ließe die Aufnahme von Staatsangehörigen von Staaten mit einer sozialistischen Wirtschaftsordnung in die Verzeichnisse zu, ja würde sie sogar vorschreiben.

Die namhaft gemachten Personen müssen ein hohes sittliches Ansehen sowie eine anerkannte Befähigung auf dem Gebiete des Rechts, des Handels, der Industrie oder des Finanzwesens besitzen, wobei hinsichtlich der für das Schiedsrichterverzeichnis benannten Personen die Befähigung auf dem Gebiet des Rechts besonders betont wird ${ }^{126}$. Diese Bestimmung erscheint gerade bei Investitionsstreitigkeiten bedeutsam, wie der Fall der Lena Goldfield Arbitration gezeigt hatte ${ }^{\mathbf{1 2 7}}$. Hier einigten sich zunächst beide Parteien auf die Bestellung des bekannten Geologen Professor Dr. Otto Stutzer als Oberschiedsrichter (umpire), der über die der Gesellschaft zustehende Entschädigungssumme erkennen sollte. Nachdem aber noch vor Einleitung des Verfahrens die Rechtsfrage der vorzeitigen Auflösung des Konzessionsvertrages aufgetaucht war, verweigerte die Sowjetregierung ihre Teilnahme am Schiedsgericht u. a. mit der Begründung, daß bei Kenntnis der in der Folge aufgetretenen Fragen die Parteien keinen Geologen, sondern „a more appropriate specialist" gewählt hätten ${ }^{128}$. Der Schiedsspruch erging in Abwesenheit des sowjetischen Schiedsrichters und wurde von der Sowjetunion nicht anerkannt ${ }^{129}$.

Wie im Rahmen des Haager Schiedshofes gelten die Ernennungen für sechs Jahre und können erneuert werden. Die Konvention enthält keine Beschränkung auf die Staatangehörigen der Vertragsstaaten, so daß auch Staatsangehörige solcher Staaten, die Nichtmitglieder der Konvention sind, sofern sie die Voraussetzungen erfüllen, als Schiedsrichter oder Vermittler namhaft gemacht werden könnten ${ }^{\mathbf{1 3 0}}$. Zu über-

120 Art. 6 Abs. 3: „Ferner übt der Verwaltungsrat alle sonstigen Aufgaben aus, die er zur Durchführung dieses Ubereinkommens für erforderlich hält."

Art. 6 Abs. 1 lit. e: „... er bestimmt die Anstellungsbedingungen für den Generalsekretär und die stellvertretenden Generalsekretäre."

121 Ahnlich auch Roulet, a. a. O., S. 132

122 Art. 3

123 Art. 13 Abs. 1

124 Art. 13 Abs. 2

125 Art. 14 Abs. 2.

126 Art. 14 Abs. 1

$127 \mathrm{Vgl}$. oben S, 269

128 Zitiert bei F. Ssekandi, Contracts between a State and a Foreign Private Company. Reflections on the Effectiveness of the Arbitration Process. 2 East African Law Journal No. 4, 1966, S. 285.

129 Annual Digest 1929/30, S. 4 und $426 \mathrm{ff}$; Stuyt, a. a. O., Nr. 370.

130 So machte Mauretanien den französischen Schiedsrichter Prof. Berger-Vachon namhaft, bevor Frankreich die Konvention ratifiziert hatte. Darüber siehe unten S. 298. 
legen wäre jedoch der Fall der Namhaftmachung eines Angehörigen eines Nichtmitgliedes der Weltbank, z. B. eines sowjetischen Schiedsrichters. Unter Berücksichtigung der erwähnten Bestimmung des Art. 14 Abs. 2 und des die Konvention beherrschenden Prinzips der Parteiautonomie ${ }^{131}$ wird wohl auch eine solche Namhaftmachung zulässig sein, da überdies die freie Wahl der Schiedsrichter ein essentielles Kriterium der internationalen Schiedsgerichtsbarkeit seit ihren Anfängen darstellt. Bis zum gegenwärtigen Zeitpunkt wurden 63 Personen als Vermittler und 66 Personen als Schiedsrichter dem Generalsekretär für die Aufnahme in die Verzeichnisse notifiziert ${ }^{132}$.

\section{b. Subjektive und objektive Grenzen der Zuständigkeit}

Unter "Zuständigkeit des Zentrums" (Jurisdiction of the Centre) wird im weiteren Sinn von den Schöpfern der Konvention jener Bereich verstanden, innerhalb welchem die Normen der Konvention Anwendung finden, und die Einrichtungen des Zentrums den Parteien für Schiedsgerichts- und Vergleichsverfahren zur Verfügung stehen ${ }^{133}$. S t r i t u se n s u handelt es sich jedoch nicht um eine Zuständigkeit der Organisation, da dieselbe, wie erwähnt, keinerlei Rechtssprechungsoder Vermittlungsfunktion ausübt, sondern um die Zuständigkeit der durch M i t w i r k u n g der Organisation errichteten Schieds- oder Vermittlungsinstanzen. In diesem Sinne ist der in der Folge verwendete Begriff der Zuständigkeit zu verstehen.

Obwohl Kapitel II der Konvention lediglich drei Artikel ${ }^{134}$ umfaßt, stellt es doch das Kernstück des Vertragswerkes dar und verdient deshalb besondere Beachtung. Aus systematischen Gründen erscheint es zweckmäßig, nach persönlichen und sachlichen Kriterien die Zuständigkeit des Zentrums abzugrenzen, wobei ersteren die subjektiven Voraussetzungen, wie Konsens und Parteifähigkeit und letzteren die Rechtsnatur des Streites zum Zwecke der gegenständlichen Untersuchung zugeordnet werden.

\section{aa. Das Konsensprinzip}

Ein Blick auf die Entwicklung der sogenannten obligatorischen Gerichtsbarkeit seit 1941 zeigt im internationalen Bereich eine sinkende Bereitschaft der Staaten a p ri or i künftig entstehende Streitigkeiten der Entscheidung einer Drittinstanz zu unterwerfen. Beweis dafür sind nicht nur die spärlichen Unterwerfungserklärungen unter das System der Fakultativklausel des Statuts des IG und die überdies vorgebrachten Reservationen ${ }^{135}$, sondern auch die geringe Zahl der seit dem Ende des zweiten Weltkrieges abgeschlossenen (generellen) Schiedsgerichtsverträge ${ }^{136}$ und die zahlreichen Vorbehalte zu Schiedsklauseln in multilateralen Verträgen ${ }^{137}$. Die die

131 Siehe unten S. $281 \mathrm{f}$.

132 ICSID, Membership of Panels, herausgegeben am 15. Februar 1968.

$133 § 22$ des Berichts.

134 Art. 25-27.

135 Sir Humphrey Waldock, Decline of the Optional Clause, in: XXXII BYIL (1955/56), S. $244 \mathrm{ff}$.

136 Zwischen 1949 und 1962 wurden nur acht solcher Verträge abgeschlossen. "A survey of treaty provisions for the pacific settlement of international disputes. 1949-1962“, United "Nations, New York 1966. Im folgenden "UN Survey 1966", S. 1.

137 Siehe Vorbehalte zu Art. IX der Konvention zur Verhütung und Bestrafung des Völkermordes, UN Survey 1966, S. 521; ferner zu Art. IX der Konvention über die politischen Rechte der Frauen, op. cit., S. 545 . 
Zwischenkriegszeit charakterisierte Überbetonung der Zwangsjurisdiktion internationaler Rechtssprechungsinstanzen als besonders geeignetes Mittel zur Verhütung von zwischenstaatlicher Gewaltanwendung dürfte, wie jüngst richtig betont wurde ${ }^{138}$, als „Bestes der Feind des Guten“ gewesen zu sein und nach der Katastrophe des zweiten Weltkrieges eine rückläufige Tendenz in dieser Hinsicht bewirkt haben ${ }^{139}$. Auch die Emanzipation der Völker Asiens und Afrikas weist in diese Richtung: nur wenige Neustaaten sind bereit, sich pro fut u ro internationalen Rechtssprechungsinstanzen $\mathrm{zu}$ unterwerfen, wobei nicht zuletzt das Mißtrauen gegen die Anwendung solcher Normen, an deren Entstehung diese Staaten keinen Anteil hatten, einen entscheidenden Faktor darstellt ${ }^{140}$. Diese Haltung kommt durch eine besondere Betonung des Konsensprinzipes zum Ausdruck, die auch bei grundsätzlicher Annahme einer schiedsgerichtlichen Beilegung von internationalen Streitigkeiten den Abschluß eines Kompromissums nach Entstehen des Streitfalles zur Voraussetzung macht. $\mathrm{Zu}$ erwähnen sei in diesem Zusammenhang der im Rahmen der Organisation der Afrikanischen Einheit vorgesehene Schiedsgerichtsmechanismus ${ }^{141}$, der den Streitparteien nur nach ausdrücklicher, in Form eines Kompromissums gegebener Zustimmung, den Streit schiedsgerichtlich beilegen $\mathrm{zu}$ wollen und den Schiedsspruch als rechtlich bindend anzusehen ${ }^{142}$, zur Verfügung steht. Auf diese Weise bedarf es daher einer doppelten Zustimmung des Staates, ehe der Schiedsgerichtsmechanismus tätig werden kann.

Auf Grund dieser seit $1945 \mathrm{zu}$ beobachtenden Tendenz wird es verständlich, daß bei Schaffung einer neuen internationalen Rechtssprechungsinstanz dem Konsensprinzip ein breiter Raum gegeben werden mußte. In der Tat ist dieses Prinzip der Angelpunkt der Zuständigkeit des Zentrums ${ }^{143}$. Die Annahme der Konvention ${ }^{144}$ durch eine verhältnismäßig große Zahl von Staaten ist nicht zuletzt darauf zurückzuführen, daß allein durch die Ratifikation der Konvention keine wie immer geartete Form einer obligatorischen Schiedsgerichtsbarkeit begründet wird ${ }^{145}$, sondern daß es den Vertragsstaaten in der Folge überlassen bleibt, von den durch die Konvention geschaffenen Schiedsgerichts- und Vergleichseinrichtungen des Zentrums auf freiwilliger Basis Gebrauch zu machen.

Grundvoraussetzung für die Zuständigkeit des Zentrums ist somit die Einwilligung der Parteien, ihre Streitigkeiten dem Zentrum zu unterbreiten, wobei diese in schriftlicher Form abgegeben werden muß ${ }^{146}$. Nähere Vorschriften in Hinblick auf Form und Zeitpunkt enthält die Konvention nicht, doch zeigt die bisherige Praxis, daß die Unterwerfungsvereinbarung in Form einer Schieds- oder kompro-

138 Durch die "Study Group on Peaceful Settlement of Disputes“; siehe S. 38 des Reports; dieser unter der Auspizien des David Davies Memorial Institute of International Studies errichteten Studiengruppe gehörten Persönlichkeiten wie die Professoren Sir Humphrey Waldock und R. Jennings, ferner Dr. D. Bowett, Dr. F. A. Mann u. a. m. an. Die Ergebnisse wurde 1966 in dem zitierten Bericht veröffentlicht.

139 Vgl. auch das Schicksal des von der International Law Commission der OVN ausgearbeiteten Entwurfes eines "Abkommens über schiedsgerichtliches Verfahren " (Convention on Arbitral Procedure), welches für die Vertragsstaaten eine unmittelbare Verpflichtung zur schiedsgerichtlichen Beilegung von Streitfällen vorgesehen hätte, aber am Widerstand insbesondere der Ostblockstaaten und einiger südamerikanischer Staaten scheiterte, da es deren Auffassung nach d a s Grundprinzip der Schiedsgerichtsbarkeit, nämlich die Willensautonomie verletze. Dazu Hazel Fox in: Report of a Study Group, S. $97 \mathrm{ff}$.

140 Op. cit., S. 57.

141 Art. XIX der am 25. Mai 1963 in Addis Abeba unterzeichneten Charter, in: UN Survey 1966, S. 78; ferner 58 AJIL (1964), S. $873 \mathrm{ff}$.

142 Art. XXIX des "Protocol of the Commission of Mediation, Conciliation and Arbitration ${ }^{\star}$ vom 21. Juli 1964. Dieser Vertrag enthält Ausführungsbestimmungen zu Art. XIX der Charter und ist deren integrierender Bestandteil.

$143 \int 23$ des Berichtes: "Consent of the parties is the cornerstone of the jurisdiction of the Centre ..."

144 Siehe unten S. 297. 145 Der Senat der Vereinigten Staaten stimmte am 16. Mai 1966 einhellig für die Ratifikation. Von Interesse ist das dem Senat gegenüber abgegebene Statement des Rechtsberaters des US-Außenministeriums,

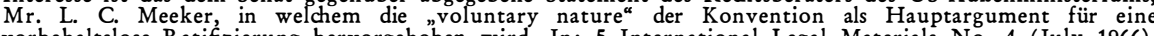
vorbehaltslose Ratifizierung hervorgehoben wird. In: 5 International Legal Materials No. 4 (July 1966), S. $646 \mathrm{ff}$. und 673

146 Art. 25 Abs. 1. 
missarischen Klausel in den Verträgen zwischen Anlagestaat und Investor aufgenommen wurde ${ }^{147}$. Darüber hinaus wäre denkbar, daß eine solche Zustimmungserklärung durch innerstaatlichen Akt z. B. der Gesetzgebung erfolgt und vom ausländischen Investor als Offerte angenommen wird ${ }^{148}$. Vorgeschlagen wurde auch die Zuständigkeitsvereinbarung durch völkerrechtlichen Vertrag zwischen einem kapitalexportierenden Staat und dem Entwicklungsland zu Gunsten der privaten Investoren ${ }^{149}$. Abgesehen davon, daß ein solcher Vertrag eine $r$ es in te $r$ a lios a c $t$ a darstellen würde, zu dessen Wirksamkeit vor dem Zentrum der in Frage kommende Investor noch zustimmen müßte, so würde dadurch das hervorgerufen werden, was die Konvention gerade vermeiden wollte: daß nämlich der Rechtsstreit zwischen Anlagestaat und Investor durch das Hinzutreten des Heimatstaates des letzteren $\mathrm{zu}$ einer politischen Angelegenheit auf zwischenstaatlicher Ebene wird.

Die Unterwerfungsvereinbarung kann auch ad hoc erfolgen, nachdem der Streitfall bereits entstanden ist. Die Konvention überläßt somit auch die Bestimmung des Zeitpunktes der Unterwerfungsvereinbarung dem Willen der Parteien, aber knüpft daran lediglich das Erfordernis der Schriftlichkeit.

Die einvernehmliche Unterwerfung kann sich entweder auf das Vergleichsverfahren oder das Schiedsverfahren isoliert erstrecken oder fakultativ beide Streitschlichtungswege vorsehen. Schließlich können sich die Parteien obligatorisch sowohl der Vergleichsinstanz als auch der Schiedsgerichtsbarkeit unterwerfen ${ }^{\mathbf{1 5 0}}$.

Von Bedeutung ist nun in diesem Zusammenhang die Frage der Rechtsnatur solcher einvernehmlicher Unterwerfungserklärungen zwischen Staaten und Privatpersonen. Wenn auch behauptet wurde, daß die Verbindlichkeit von Verträgen zwischen Staaten und Einzelpersonen bei widersprechenden "nationalen Interessen“ ihre Grenze habe ${ }^{151}$ und daher vom Staat einseitig aufgehoben werden können, so ergibt sich aus der rechtstheoretischen Konzeption hier eine verschiedene Rechtslage. Die durch die Unterwerfungsvereinbarung erzeugte gegenseitige Verbindlichkeit beruht nicht mehr ausschließlich auf dem Vertrag zwischen den Parteien, sondern kann als Durchführung einer höheren Norm, nämlich der des Art. 25 Abs. 1 der Konvention angesehen werden; es ist daher Völkerrecht die bestimmende Rechtsordnung, der diese Verpflichtung unmittelbar unterworfen ist ${ }^{152}$. Eine Reihe von weiteren Bestimmungen unterstreicht diese „Konsensstrenge“ der Konvention: ist einmal eine Unterwerfungsvereinbarung abgeschlossen worden, dann kann keine der Parteien sie einseitig rückgängig machen ${ }^{153}$. Weigert sich eine Partei an der Zusammensetzung der Vergleichskommission oder des Schiedsgerichts mitzuwirken, so geht das Ernennungsrecht der fehlenden Vermittler 154 oder Schiedsrichter ${ }^{155}$ auf Antrag der anderen Partei auf den Vorsitzenden des Verwaltungsrates über156. Weiter können Schiedssprüche auch in Abwesenheit einer der Parteien gefällt werden ${ }^{157}$ und schließlich bestimmt die Konvention, daß Schiedssprüche wie

$147 \mathrm{Vgl}$. die in der Dokumentation angeführten Beispiele.

148 Amadio, a. a. O., S. 128; Roulet, a. a. O., S. 136. Vgl. dazu das afghanische Investitionsförderungsgesetz vom 20. Januar 1967. Siehe unten S. 331.

149 So von Berger, a. a. O., S. 439.

$150 \mathrm{Vgl}$. Art. 18 des Vertrages zwischen Mauretanien und der Société Planet Oil and Mineral Corporation. Dokumentation S. 329.

151 Dazu die oben S. 262 angeführte Literatur.

152 Richtig Amadio, a. a. O., S. 131: "... Le consentement a la valeur d'une obligation internatıonal. C'est un acte détachable dont le régime juridique est fixé de façon intangible, quelle que soit la nature juridique de l'instrument que le porte."

153 Art. 25 Abs. 1, letzer Satz.

154 Art. 30.

156 Vgl. oben S. 277.

157 Art. 45 Abs. 2. 
„ein endgültiges Urteil der innerstaatlichen Gerichte der Vertragsstaaten“ zu behandeln seien ${ }^{158}$.

Diesen im Interesse des Investors geschaffenen Bestimmungen steht das Verbot der Vertragsstaaten gegenüber, einen ihrer Angehörigen im Falle der Unterwerfung unter die schiedsgerichtliche Jurisdiktion des Zentrums diplomatischen Schutz zu gewähren ${ }^{159}$. Dieser Verzicht des Heimatstaates auf Ausübung seines diplomatischen Schutzrechtes ist in $s$ ubstantia die Rezeption der CalvoKlausel in einen völkerrechtlichen Vertrag und dient im konkreten Falle der Verhinderung der Einmischung des Heimatstaates in das anhängige Schiedsverfahren, dessen sachlich-rechtliche Elemente von politischen Interzessionen freigehalten werden sollten. Doch dieser Verzicht gilt nicht unbeschränkt: nach Beendigung des Schiedsverfahrens und Erlassung des Schiedsspruches lebt das Schutzrecht des Heimatstaates wieder auf, falls der ,andere Vertragsstaat den in der Streitsache erlassenen Schiedsspruch nicht befolgt" ${ }^{\mathbf{1 6 0}}$. Eine parallele Bestimmung in Hinblick auf das Vergleichsverfahren fehlt, so daß in Verbindung mit Art. 27 Abs. 2 e c on tra ri o geschlossen werden darf, daß die Schöpfer der Konvention den Verzicht der Vertragsstaaten auf Ausübung ihres Schutzrechtes ausdrücklich auf das schiedsgerichtliche Verfahren beschränken wollten ${ }^{161}$. Damit sollte es dem Heimatstaat des Investors offen gelassen bleiben, durch geeignete Vermittlungsvorschläge auch zu einer raschen Beilegung des Streitfalles beizutragen.

Eine weitere, nur das Schiedsverfahren betreffende Regelung stellt der bei schiedsgerichtlicher Unterwerfung impliziert angenommene Verzicht auf Beschreitung anderer Wege zur Streitbeilegung ${ }^{\mathbf{1 6 2}}$ dar; diese Bestimmung schließt nicht nur die gleichzeitige Annahme anderer internationaler Streitbeilegungsmethoden, wie sie z. B. durch den Ständigen Haager Schiedshof ${ }^{163}$ oder nach Inkrafttreten des OECDProjektes ${ }^{164}$ vorgesehen sind, aus, sondern dispensiert auch i m plic it e von dem Erfordernis der Erschöpfung des innerstaatlichen Instanzenzuges, sofern im letzteren Falle die Parteien keine gegenteilige Vereinbarung getroffen haben ${ }^{\mathbf{1 6 5}}$. Fehlt daher eine im Zusammenhang mit der Unterwerfungsvereinbarung abgegebene Erklärung seitens des beteiligten Staates hinsichtlich des Erfordernisses der Erschöpfung des innerstaatlichen Instanzenzuges, so kann sich der Investor im Falle einer Streitigkeit unmittelbar an das Zentrum wenden und dem gegnerischen Staat ist diese Einrede verwehrt. Die $\mathrm{r}$ a $\mathrm{t}$ i o dieser Bestimmung liegt wohl darin, daß bei Investitionsstreitigkeiten, die vielfach in Rechtsakten oberster Organe des Anlagestaates ihre Wurzeln haben, eine Rechtsverfolgung im innerstaatlichen Bereich aussichtslos erscheint und eine unnötige Verzögerung für den Investor bedeuten würde. Auch wird in vielen Fällen das innerstaatliche Rechtsschutzsystem - gemessen am internationalen Standard - für solche Streitigkeiten sich als ungeeignet erweisen.

Obwohl in den Vorarbeiten zur Konvention eine Reihe von Staaten auf die obligatorische Beibehaltung des Prinzips der Erschöpfung des innerstaatlichen Instanzenzuges bestanden hatten ${ }^{166}$, wurde schließlich durch Art. 26 eine Kompromißlösung geschaffen, die zwar dieses Erfordernis für die Zuständigkeit des

158 Art. 54 Abs. 1.

159 Art. 27 Abs. 1

160 Art. 27 Abs. 1, letzter Satz.

161 Diese Interpretation ergibt sich auch aus $\int 33$ des Berichts. Jedoch anderer Meinung Amadio, der die Beschränkung des Heimatstaates auch auf das Vergleichsverfahren ausdehnen will; a. a. O., S. 135 und 137.

162 Art. 26, erster Satz.

164 Vgl. oben Fußnote 24, S. 267, und unten S. 301.

165 Art. 26, zweiter Satz.

166 Roulet, a. a. O., S. 135. 
Schiedsgerichtes nicht zur Prozeßvoraussetzung machte, doch dem beteiligten Staat das Recht zuerkannte, darauf zu bestehen, womit auch durch diese Bestimmung der Parteiautonomie großer Spielraum gegeben wurde ${ }^{\mathbf{1 6 7}}$.

Es darf in diesem Zusammenhang daran erinnert werden, daß eine Dispens vom Erfordernis der Erschöpfung des internationalen Instanzenzuges in der Geschichte der internationalen Schiedsgerichtsbarkeit durchaus kein Novum darstellt; bereits vor dem ersten Weltkrieg verzichteten die Vereinigten Staaten und Großbritannien auf diese Regel in den dem Schiedsvergleich vom 18. August 1910 angeschlossenen „Terms of Submission“ vom 6. Juli 1911, wodurch eine gemischte Schiedskommission errichtet wurde, die vornehmlich über Ansprüche der Staatsangehörigen beider Staaten gegen den anderen Staat entscheiden sollte, die während der vergangenen Kriege (Spanisch-Amerikanischer Krieg und Burenkrieg) entstanden waren ${ }^{168}$. Die nach dem ersten Weltkrieg zwischen Mexiko und einer Reihe von Staaten abgeschlossenen Verträge zur Errichtung von Mixed Claims Commissions enthielten gleichfalls einen solchen Verzicht auf das Erfordernis der Erschöpfung des innerstaatlichen Instanzenzuges ${ }^{169}$, dessen Formulierung fast wörtlich der des erstgenannten Beispieles gleicht.

Zusammenfassend kann somit festgehalten werden, daß durch besondere Betonung des Konsensprinzips die Konvention den Bedürfnissen der gegenwärtigen Staatenwelt weitgehend Rechnung trägt; erfolgt aber eine Unterwerfung unter die Jurisdiktion des Zentrums, dann ist der gegebene obligatorische Mechanismus der Konvention geeignet, eine rasche und wirksame Beilegung des Streites herbeizuführen.

\section{bb. Die Parteien}

Wie des öfteren erwähnt, ist die Konvention dadurch gekennzeichnet, daß sie vergleichs- und schiedsgerichtliche Einrichtungen schafft, deren Kompetenz auf Personen verschiedener internationaler Rangstufe sich erstreckt: auf der einen Seite ist es ein Vertragsstaat oder eine von diesem dem Zentrum benannte Gebietskörperschaft (constituent subdivision, collectivité publique) oder eine staatliche Stelle (agency, organisme dépendent), welchen durch Art. 25 Abs. 1 Parteifähigkeit zuerkannt wird. Obwohl zunächst nur Staaten vorgesehen waren, erschien nach den Ergebnissen der Regionalversammlung von Addis Abbeba ${ }^{170}$ die Ausdehnung auch auf Gebietskörperschaften und ganz allgemein auf „staatliche Stellen“ als notwendig, da in einer Reihe von bundesstaatlich organisierten Neustaaten die Kompetenz in Hinblick auf ausländische Kapitalanlagen vollständig oder zum Teil den Gliedstaaten übertragen wurde und auch gelegentlich eigenen Behörden (z. B. national investment boards) eine Zuständigkeit hinsichtlich solcher Agenden einge-

$167 \mathrm{Vgl}$. dazu den Vertrag zwischen Alusuisse und Island. Dokumentation, S. 330.

$168 \mathrm{Im}$ Anschluß an das am 18. August 1910 abgeschlossene „Agreement between the United Kingdom and the United States of America for the Settlement of various Pecuniary Claims outstanding between the two Governments“ wurde am 6. Juli 1911 durch Ziffer 3 der "Terms of Submission“ i n t e r a li a festgelegt: “... no claim shall be disallowed or rejected by application of the general principle of international law that the legal remedies must be exhausted as a condition precedent to the validity of the claim." British Parl. Pap. (Cd. 5803), August 1911, S. 7; Stuyt, No. 303 .

169 So Art. 6 des Schiedsgerichtsvergleichs zwischen Mexiko und den Vereinigten Staaten vom 10. September 1923, der wörtlich in die Verträge mit Frankreich (25. 11. 1924), Deutschland (16. 3. 1925), Spanien (25. 11. 1925), Großbritannien (19. 11. 1926) und Italien (13. 1. 1927) übernommen wurde: "... the Mexican Government agrees that the Commission shall not disallow or reject any claims by the application of the general principle of international law that the legal remedies must be exhausted as a condition precedent to the validity or allowance of any claim", Stutyt, $\mathrm{Nr} .355$.

170 Roulet, a. a. O., S. 138. 
räumt wird ${ }^{171}$. Um eine Überprüfung innerstaatlicher Kompetenzvorschriften seitens der Vergleichs- oder Schiedsinstanz des Zentrums zu vermeiden, bestimmt die Konvention, daß nur dem Zentrum von den Vertragsstaaten notifizierte Gebietskörperschaften und „staatliche Stellen“ Parteiqualität besitzen. Diese können mit dem ausländischen Investor Unterwerfungsvereinbarungen vorbehaltlich der Zustimmung des Vertragsstaates abschließen ${ }^{172}$; eine solche kann für jeden einzelnen Vertrag ad hoc gegeben werden oder es wird durch den Vertragsstaat dem Zentrum notifiziert, daß eine Genehmigung desselben für Verträge seiner Gebietskörperschaften und staatlichen Stellen nicht erforderlich sei ${ }^{173}$. In solchen Fällen stellt somit die Vergleichs- oder Schiedskommission rein formell die Parteiqualität durch Prüfung des Vorhandsens einer individuellen oder generellen Genehmigung seitens des Vertragsstaates fest ${ }^{174}$, ohne in die heikle Frage eingehen zu müssen, ob die betreffende Gebietskörperschaft oder staatliche Stelle nach innerstaatlichem Recht überhaupt befugt gewesen wäre, mit dem ausländischen Investor solche Vereinbarungen einzugehen. Weiter dient diese Bestimmung insofern der Rechtssicherheit, als der Anlagestaat nach erteilter Vertragsgenehmigung die Gültigkeit von solchen Verträgen nicht mehr wirksam bestreiten kann ${ }^{175}$.

Während somit auf der einen Seite Staaten oder von einem Vertragsstaat delegierte Rechtseinheiten vor dem Zentrum als Parteien auftreten, besitzen auf der anderen Seite gemäß der Bestimmung des Art. 25 Abs. 1 „Angehörige eines anderen Vertragsstaates" Parteiqualität; als solche sind physische und juristische Personen zu verstehen, welche eine andere Staatsangehörigkeit als die des am Streit beteiligten Vertragsstaates besitzen, wobei die Konvention hinsichtlich des Zeitpunktes, zu welchem dieses Staatangehörigkeitselement vorliegen muß, einen deutlichen Unterschied zwischen physischen und juristischen Personen macht. Während physische Personen die Staatsangehörigkeit eines anderen Vertragsstaates im Zeitpunkt der Unterwerfungsvereinbarung und im Zeitpunkt der Registrierung des Antrages durch den Generalsekretär besitzen müssen, entfällt bei juristischen Personen letzteres Erfordernis ${ }^{176}$; da somit die Konvention von juristischen Personen die fremde Staatangehörigkeit $\mathrm{n} \mathrm{u} \mathrm{r}$ im Zeitpunkt der Unterwerfungsvereinbarung verlangt, ist ein locus standi vor dem Vergleichs- und schiedsgerichtlichen Instanzen auch für solche Gesellschaften gegeben, die in der Folge eine andere Staatsangehörigkeit - unter Umständen auch die des am Streit beteiligten Staates - erworben haben ${ }^{177}$. Eine weitere Begünstigung juristischer Personen gegenüber physischen sieht die Konvention für den Fall der Doppelbürgerschaft (nämlich des Anlagestaates und des anderen Vertragsstaates) vor: während natürlichen Personen unter solchen Umständen der Zugang zum Zentrum versperrt ist, erstreckt sich die Zuständigkeit des Zentrums auch auf juristische Personen, welche die StaatsangeL.örigk-eit des am Streit beteiligten Staates besitzen, sofern „die Parteien übereingekommen sind, diese juristische Person wegen ausländischer Kontrolle als Staatsangehörige eines anderen Vertragsstaates im Sinne dieser Konvention zu betrachten "178.

171 Der Ausdruck „staatliche Stellen“ (agency) wurde bewußt unklar gewählt, um die Fülle der Erscheinungsformen hoheitlicher und privater Tätigkeit des Staates zu erfassen. Dazu Delaume, a. a. O., S. 34. 172 Art. 25 Abs. 3.

173 Id.

174 Vgl. Rule 2 der "Verfahrensordnung für die Einleitung von Vergleichs- und Schiedsverfahren“: "The request shall ... Indicate the date of consent and the instruments in which it is recorded, including, if one party is a constituent subdivision or agency of a Contracting State, similar data on the approval is required." ICSID $/ 4$, S. 29.

175 Vgl. dazu Amadio, a. a. O., S. 103 ff.

176 Art. 25 Abs. 2 lit. a und b.

177 So auch Amadio, a. a. O., S. 113; andere Meinung Berger, a. a. O., S. 439, Fußnote 11, welcher trotz Fehlen einer analogen Bestimmung eine sinngemäße Anwendung auf juristische Personen annimmt.

178 Art. 25 Abs. 2 lit. b, letzter Satz. 
Daraus ergibt sich, daß die Konvention der juristischen Person im Verhältnis zur physischen eine bevorzugte Stellung zuerkennt: während das Prinzip der "nationality of claims" bei physischen Personen streng eingehalten wird, erfährt es bei juristischen Personen insofern eine Einschränkung, als diese zum Zeitpunkt der Einleitung des Verfahrens nicht mehr unbedingt die fremde Staatsbürgerschaft besitzen müssen und auch als Doppelbürger vom Verfahren nicht ausgeschlossen sind. Beide Bestimmungen liegen im Interesse des ausländischen Investors, wobei letztere dem Schutz jener ausländischen Gesellschaft dient, die zugleich auch die Staatsangehörigkeit des Anlagestaates besitzt; in dieser Hinsicht entspricht die Konvention einem Bedürfnis der Praxis, da Investitionsgesellschaften häufig auch als inländische Gesellschaften des Anlagestaates registriert werden ${ }^{179}$, bzw. gelegentlich eine solche "Naturalisierung " durch die innerstaatliche Rechtsordnung des Anlagestaates für die Erteilung des Niederlassungsrechtes zur Voraussetzung gemacht wird $^{180}$. Die Konvention enthält allerdings kein allgemeines Kriterium zur Bestimmung der Staatsangehörigkeit von juristischen Personen ${ }^{181}$, sondern verweist indirekt auf das innerstaatliche Recht des anderen Vertragsstaates ${ }^{182}$. Wohl erwähnt Art. 25 Abs. 2 lit. b das Anknüpfungsmoment der "ausländischen Kontrolle“ im Zeitpunkt der Unterwerfungsvereinbarung; doch gilt dies nur für solche Fälle, in denen die Parteien auf Grund der Tatsache, daß eine bestimmte juristische Person die Staatsangehörigkeit des Anlagestaates besitzt, erklären, dieselbe zur bloßen Zuständigkeitsbegründung des Zentrums als Staatsangehörige eines anderen Vertragsstaates zu betrachten ${ }^{183}$ : Ob diese Regel auch bei Fehlen einer solchen Parteienvereinbarung gilt, bleibt offen. Gleichermaßen erhebt sich die Frage, ob die Bestimmung der Staatszugehörigkeit der juristischen Person durch die Parteien auch dann rechtswirksam ist, wenn z. B. der betroffene Staat das Anknüpfungsmoment der ausländischen Kontrolle nicht kennt, sondern für ihn z. B. das Recht des Gründungsaktes maßgebend ist. Ein Beispiel soll diesen Fall erläutern: wird vereinbart, daß eine im Nichtvertragsstaat A registrierte Gesellschaft, deren Aktienmajorität in Händen von Staatsangehörigen des Vertragsstaates B liegt, dessen Rechtsordnung wiederum auf das Recht des Nichtvertragsstaates A verweist, als eine im Sinne der Konvention als Gesellschaft des Staates B angesehen werden soll, so stellt sich das Problem, ob eine solche Vereinbarung für die Zuständigkeitsbegründung des Zentrums zureichend ist. Diese Frage wird wohl der Judikatur der Schiedsgerichte $\mathrm{zu}$ überlassen sein, doch ist anzunehmen, daß nicht zuletzt auch in Hinblick auf die positive Entscheidung des IGH vom 24. Juli 1964 in der Zuständigkeitsfrage im Falle Barcelona Traction, Light and Power Company Ltd. ${ }^{184}$ eine solche Zuständigkeitsvereinbarung als rechtswirksam erkannt wird. Bedenklich ist hingegen eine Vereinbarung, die zwar „wegen ausländischer Kontrolle“ eine bestimmte Gesellschaft, welche die Staatszugehörigkeit des Anlagestaates besitzt, als ausländische anerkennt, aber verabsäumt zu bestimmen, welchem Staat sie im Sinne der Konvention zuzuordnen ist ${ }^{185}$. Da sowohl Art. 25. Abs. 2 lit. b (letzter Satz) als auch die auf Grund dieser Bestimmung ergangene Rule 2 der Verfahrensordnung

179 Siehe Dokumentation, S. 329.

180 So z. B. Madagaskar und Guinea. Roulet, a. a. O., S. 139

181 Allgemein siehe zu diesem Problem K. Ginther, Nationality of Corporations, in: Osterreichische Zeitschrift für Offentliches Recht, Bd. XVI/1-2 (1966), S. $27 \mathrm{ff}$. und die dort angeführte Literatur.

182 Richtig Berger, a. a. O., S. 439.

183 Treffend Amadio, der eine solche, nur zum Zwecke der Zuständigkeitsbegründung, vereinbarte Staatszugehörigkeit als "une sorte de nationalité fonctionelle“ bezeichnet. A. a. O., S. 115.

184 ICJ Reports 1964, S. 6 ff.

185 Vgl. Art. 50 zwischen der ,Société des mines de Mauritanie“ und Mauretanien vom 18. Juli 1967. Dazu unten in der Dokumentation, S. 329. 
für die Einleitung von Vergleichs- und Schiedsverfahren ${ }^{186}$ ausdrücklich die Benennung des anderen Vertragsstaates erfordern, darf angenommen werden, daß eine solche Unterwerfungserklärung zumindest unvollständig und daher zur Zuständigkeitsbegründung ungeeignet ist.

Keine Bestimmung enthält die Konvention in Hinsicht auf das seit 1945 in einigen kapitalexportierenden Staaten ${ }^{187}$ entwickelte Versicherungssystem gegen nichtkommerzielle Risiken, die den Heimatstaat des Investors bei Schädigung der Kapitalanlage durch Akte des Gaststaates und nachfolgender Ersatzleistung des Heimatstaates diesen in die Rechtsstellung des Investors eintreten lassen. In einem solchen Falle dürfte selbst mit Zustimmung des Anlagestaates die schiedsgerichtliche Geltendmachung des Anspruches vor dem Zentrum ausgeschlossen sein, da die Konvention das Individuum als Prozeßpartei zwingend vorschreibt. Ist hingegen Versicherungsträger nicht der Heimatstaat, sondern eine private Gesellschaft, dann erscheint einer Geltendmachung des zedierten Anspruches vor dem Zentrum nichts entgegenzustehen; als Ausfluß des absoluten Konsensprinzipes bedarf es jedoch auch hier der Zustimmung des Anlagestaates ${ }^{188}$.

Zusammenfassend kann somit festgehalten werden, daß das Konsensprinzip die Grundvoraussetzung jeglichen Tätigwerdens des durch die Konvention geschaffenen Vergleichs- und Schiedsgerichtsmechanismus darstellt, daß weiter letzterer nur Streitigkeiten zwischen Privatpersonen (physischen und juristischen) und Staaten offensteht, wodurch die Zuständigkeit des Zentrums in subjektiver Hinsicht abgegegrenzt ist.

\section{cc. Die Rechtsnatur des Streites}

In sachlicher Hinsicht erstreckt sich die Kompetenz des Zentrums auf „alle unmittelbar mit einer Investition zusammenhängenden Rechtsstreitigkeiten "189. Darunter werden von den Schöpfern der Konvention im Sinne von Art. 36 Abs. 2 des Statuts des IG solche Streitigkeiten verstanden, welche „Bestehen oder Umfang von Rechten oder Pflichten betreffen, oder Art und Ausmaß der Wiedergutmachungspflicht für eine Rechtsverletzung zum Gegenstand haben"190. Sogenannte politische oder Interessensstreitigkeiten sind damit von der Zuständigkeit des Zentrums ausgeschlossen ${ }^{191}$.

In Hinblick darauf, daß durch die Konvention nicht nur schiedsgerichtliche, sondern auch Vergleichsinstanzen vorgesehen sind, mag es verwundern, daß auch deren Kompetenz auf Rechtsstreitigkeiten beschränkt bleibt, wodurch der Problematik langfristiger Investitionsverträge $\mathrm{zu}$ wenig Rechnung getragen wird. Denn die Praxis hat gezeigt, daß solche Verträge einer periodischen Revision und Anpassung an die geänderten Verhältnisse unterzogen werden müssen, was häufig zur Entstehung von Streitigkeiten zwischen dem sich einer solchen Revision entgegen-

\footnotetext{
186 Rule 2 (1) d (iii): “The request shall indicate with respect to the party that is a national of a Contracting State ... if the party is a juridical person which on the date of consent had the nationalty of the parties

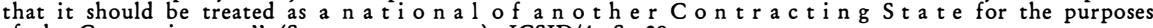
of the Convention..." (Sperrung von uns), ICSID/4, S. 29

187 Nämlich die Vereinigten Staaten, Japan und die Bundesrepublik Deutschland. Dazu Nwogugu, a. a. O., S. $71 \mathrm{ff}$.

188 So auch Amadio, a. a. O., S. 119.

189 Art. 25 Abs. 1.

190 \& 26 des Berichts.

191 Die Unterscheidung in Rechts- und politische Streitigkeiten ist eher fragwürdig, da kaum ein Rechtsstreit politischer Elemente entbehrt, doch wurde dieser Begriff deshalb gewählt, um offensichtlich rein politische, durch keine Rechtsnorm begründete Streitigkeiten a p r i o r i vom Zentrum fernzuhalten. Dazu Amadio, a. a. O., S. $93 \mathrm{ff}$.
} 
stellenden Investor und dem Anlagestaat führt ${ }^{192}$. Enthält der Vertrag keine Revisionsklausel, dann ist dieser Streitfall der Zuständigkeit des Zentrums entzogen ${ }^{193}$, wobei bemerkt werden muß, daß gerade für solche Streitigkeiten aus Revisionsansprüchen, die durch keine vertragliche Norm gedeckt sind, das Vergleichsverfahren durch die sein Wesen charakterisierende Ausgleichsfunktion eine durchaus geeignete Streitbeilegungsmethode darstellt. Eine Erweiterung der $\mathrm{Zu}-$ ständigkeit der Vergleichsinstanzen in dieser Hinsicht wäre daher wünschenswert.

Neben dem Erfordernis der Qualifikation als „Rechtsstreit“ muß die Differenz $\mathrm{zwischen}$ privatem Investor und Staat in einem direkten Kausalzusammenhang mit der Investition stehen. Die Konvention selbst gibt nicht Aufschluß darüber, was unter "Investition“ verstanden wird. Auch hier operiert wieder das Konsensprinzip, da es jedem Vertragsstaat freisteht, dem Zentrum zu notifizieren, welche Arten von Streitigkeiten er der Zuständigkeit des Zentrums zu unterwerfen beabsichtigt ${ }^{194}$. Ausdrücklich fügt jedoch die Konvention hinzu, daß eine solche Notifikation keineswegs eine Unterwerfungsvereinbarung im Sinne des Art. 25 Abs. 1 darstellt ${ }^{195}$.

Diese hier dargelegten Kompetenzvorschriften der Art. 25-27 der Konvention repräsentieren, wie bereits erwähnt, den Kern des Vertragswerkes, in welchen die wesentlichen Grundsätze, nämlich das Konsensprinzip und der Grundsatz der Prozeßgleichheit von Staat und Einzelperson enthalten sind. Inwieweit diese eine nähere Durchführung erfahren, ist jetzt zu behandeln.

\section{Das Vergleichs- und das Schiedsverfahren}

Wie bereits des öfteren erwähnt, bietet die Konvention zwei Verfahrensarten zur Beilegung von Investitionsstreitigkeiten zwischen Staaten und Einzelpersonen: das Vergleichs-196 und das Schiedsverfahren. Obwohl die gegenständliche Darstellung sich vornehmlich auf den schiedsgerichtlichen Aspekt konzentriert, sei dennoch der Vollständigkeit halber gestattet, einen Blick auf das Vergleichsverfahren zu werfen, wobei aus systematischen Gründen zunächst die gemeinsamen und sodann die für die beiden Verfahrensarten eigenen Bestimmungen erörtert werden.

Für beide Arten des Streitbeilegungsverfahrens im Rahmen der Konvention gilt der Grundsatz, daß zunächst auf diese die allgemeinen Bestimmungen der Konvention Anwendung finden. Sodann ist es den Parteien überlassen, entsprechende Verfahrensvorschriften zu vereinbaren, die allerdings nicht in Widerspruch $\mathrm{zu}$ den in der Konvention enthaltenen $\mathrm{z} w$ in $\mathrm{g}$ e $\mathrm{n}$ de $\mathrm{n}$ Normen stehen dürfen ${ }^{197}$.

192 Z. B. wurde der Vertrag zwischen Kuwait und der Kuwait Oil Company vom 23. Dezember 1934 in den Jahren 1955, 1963 und 1966 revidiert. Der Vertrag zwischen Qatar und der Anglo-Persian Oil Company vom 17. Mai 1935 wurde 1952, 1955, 1957, 1958 und 1964 einer Revision unterzogen. Dazu siehe: UN Report on Financing of Economic Development and Promoting of Private Foreign Investment in Developing Countries, UN document E/4293.

193 Auf dieses Problem hatte der Generalsekretär des Zentrums, Mr. A. Broches, in seiner Ansprache auf der ersten Jahresversammlung des Verwaltungsrates am 25. September 1967 hingewiesen und eine Kompetenzerweiterung des Zentrums auch auf solche Streitigkeiten zur Diskussion gestellt., ICSID Press Release, No. 2 , S. 3.

194 Art. 25 Abs. 4. Bisher wurde jedoch von dieser Bestimmung von keinem der Vertragsstaaten Gebrauch gemacht. ICSID, First Annual Report 1966/67, S. 14.

195 Art. 25 Abs. 4, letzter Satz.

196 Obwohl "Vergleich“ oder "Schlichtung “ in einêm engen Zusammenhang mit der Streitbeilegungsmethode "Vermittlung" steht, da in beiden Fällen eine internationale Instanz einen friedlichen Interessenausgleich herbeiführen und Vorschläge erstatten soll, ist der Unterschied darin gelegen, daß Vergleich das Vorhandensein eines geregelten Verfahrens zur Voraussetzung hat, während Vermittlung in der Regel formlos gestaltet ist. Dazu Dahm, Völkerrecht, a. a. O., Bd. II, S. 450. In Hinblick auf deren Funktion können aber die Mitglieder der Vergleichskommission als Vermittler bezeichnet werden, so daß in der Folge dieser Ausdruck im Rahmen der gegenständlichen Untersuchung verwendet wird.

197 In Hinblick auf das Schiedsverfahren unklar Berger, a. a. O., S. 440. 
Fehlt eine solche Vereinbarung, so ist die im Zeitpunkt der Unterwerfungsvereinbarung gültige Vergleichs- bzw. Schiedsordnung anzuwenden ${ }^{198}$. Verbleibt dann noch eine Verfahrensfrage ungeregelt, so erkennt die Kommission bzw, das Gericht selbst darüber ${ }^{199}$.

Die Einleitung des Verfahrens erfolgt in beiden Fällen durch schriftlichen Antrag an den Generalsekretär200, der ihn, falls keine offensichtlichen Mängel vorliegen ${ }^{201}$, registriert und der anderen Partei zuleitet. Der Antrag muß den Streitgegenstand, die Parteien und deren Unterwerfungsvereinbarung bezeichnen ${ }^{202}$. Nach erfolgter Registrierung muß sobald wie möglich ${ }^{203}$ die Vergleichskommission bzw. das Schiedsgericht gebildet werden, welches sich aus einer Einzelperson (Einzelvermittler bzw. Einzelschiedsrichter) oder einer ungeraden Anzahl von Personen (Vermittler bzw. Schiedsrichter) zusammensetzt, die nach Vereinbarung von den Parteien ernannt werden ${ }^{204}$. Bei Fehlen einer zahlenmäßigen Übereinstimmung setzt sich die Kommission bzw. das Gericht aus drei Personen zusammen, wobei jede Partei eine ernennt und der Vorsitzende in gegenseitigem Einvernehmen bestellt wird ${ }^{205}$. Um jede Verzögerung zu vermeiden, muß die Kommission bzw. das Schiedsgericht innerhalb von 90 Tagen nach Absendung der Notifikation der Registrierung gebildet sein, widrigenfalls das Ernennungsrecht in Hinblick auf die noch nicht bestellten Vermittler bzw. Schiedsrichter auf Antrag einer Partei auf den Vorsitzenden des Verwaltungsrates übergeht ${ }^{206}$. Während bei Ernennung durch die Parteien auch Personen berufen werden können, die nicht im Vermittler- bzw. Schiedsrichterverzeichnis aufgenommen sind, darf der Vorsitzende des Verwaltungsrates nur Personen aus den Verzeichnissen heranziehen ${ }^{207}$. Beiden Verfahren gemeinsam ist schließlich die Bestimmung, daß beide Instanzen über ihre Zuständigkeit selbst $\mathrm{zu}$ entscheiden berechtigt sind (Kompetenzkompetenz) und ihnen ausdrücklich das Recht zur Entscheidung eingeräumt ist, eine Unzuständigkeitseinrede als Vorfrage oder gemeinsam mit der Hauptfrage zu behandeln ${ }^{208}$.

\section{a. Das Vergleichsverfahren}

Über die Aufgaben der Vergleichskommission bestimmt die Konvention ganz allgemein, daß diese die zwischen den Parteien bestehenden Streitfragen zu klären und sich um eine annehmbare Lösung zu bemühen habe ${ }^{209}$. Die Kommission kann zu diesem Zweck in jedem Stadium des Verfahrens Empfehlungen an die Parteien richten; diese wiederum sind verpflichtet, nach „Treu und Glauben“ mit der Kommission zusammenzuarbeiten und den Empfehlungen größte Beachtung zu schenken ${ }^{210}$. Gelingt eine Einigung, so wird durch die Kommission ein Bericht angefertigt,

$198 \mathrm{Da}$ die endgültigen Verfahrensordnungen erst am 1. 1. 1968 in Kraft traten, sind daher auf die bis zu diesem Zeitpunkt geschlossenen Unterwerfungsvereinbarungen die seit 2. Februar 1967 in Kraft gestandenen vorläufigen Verfahrensordnungen anzuwenden. Doc. ICSID/4, S. 3.

199 Art. 33 bzw. Art. 44.

200 Art. 28 bzw. Art. 36.

201 Siehe dazu oben S. 278.

202 Art. 28 Abs. 2 bzw. Art. 36 Abs. 2. Diese Bestimmungen sind näher ausgeführt durch Rule 2 und 3 der Verfahrensordnung für die Einleitung von Vergleichs- und Schiedsverfahren. ICSID/4, S. $29 \mathrm{ff}$

203 Art. 29 Abs. 1 bzw. Art. 37 Abs. 1 .

204 Art. 29 Abs. 2 lit. a bzw. Art. 37 Abs. 2 lit. a.

205 Art. 29 Abs. 2 lit. b bzw. Art. 37 Abs. 2 lit. a.

206 Art. 30 und Art. 38. Im Schiedsverfahren gilt dazu die Regel, daß die vom Vorsitzenden ernannten Personen weder dem am Streit beteiligten Vertragsstaat noch dem Heimatstaat der Einzelpersonen angehören dürfen.

207 Art. 31 Abs. 1 bzw. Art. 40 Abs. 1.

208 Art. 32 bzw. Art. 41 .

209 Art. 34 Abs. 1 . Vgl. dazu auch Rule 22 und 23 der Vergleichsordnung, die diese Bestimmung näher ausführen. ICSID $/ 4$, S. 60/61.

210 Vgl. dazu auch Abs. 6 der Präambel. 
in welchem die Streitfragen und die gefundene Lösung aufscheinen. Bei Mißlingen einer Beilegung des Streites sowie im Falle des Nichterscheinens einer Partei wird gleichfalls ein Bericht angefertigt, der diese Tatsachen wiedergibt ${ }^{211}$. Von Interesse ist die, wenngleich abdingbare Regelung, daß sich keine der Parteien in einem späteren Verfahren vor einer anderen Instanz auf die vor der Vergleichskommission abgegebenen Erklärungen, Meinungsäußerungen, Zugeständnisse sowie auf Berichte oder Empfehlungen der Kommission selbst berufen kann ${ }^{212}$. Mit dieser Bestimmung soll durch zusätzliche Betonung der Unverbindlichkeit des Vergleichsverfahrens als Streitbeilegungsweg diesem ausdrücklich jedwede Präjudizwirkung genommen werden ${ }^{213}$.

Das Verfahren nach der Konvention entspricht im Wesen somit den herrschenden Grundsätzen über die Funktion von Vergleichskommissionen: Klarstellung des Sachverhalts und Erstattung von Empfehlungen sind die beiden wesentlichsten Verfahrenselemente. Naturgemäß ist die Kommission mit keinerlei Zwangsgewalt ausgestattet, sie kann lediglich das Scheitern und die Beendigung des Verfahrens zu Protokoll nehmen.

\section{b. Das Schiedsverfahren}

Während allgemein das Vergleichsverfahren als Methode zur Beilegung von internationalen Streitigkeiten die Herbeiführung eines Ausgleiches gegensätzlicher Interessen durch Erstattung von (rechtlich unverbindlichen) Vorschlägen zum Ziele hat, ist die Schiedsgerichtsbarkeit durch die Ermächtigung zur Erlassung rechtlich bindender Entscheidungen charakterisiert ${ }^{214}$; dem Schiedsgericht sind daher wesentlich weitergehende, seiner spezifischen Funktion als endgültiges Streiterledigungsorgan entsprechende Rechte eingeräumt, die in der gegenständlichen Konvention im einzelnen durch die Vorschriften über das Verfahren im engeren Sinn, über den Schiedsspruch und dessen Vollstreckung ihren Ausdruck finden und das internationale Bedürfnis nach Errichtung einer möglichst effektiven Rechtssprechungsinstanz widerspiegeln ${ }^{215}$.

Diesem Ziel dienen nicht nur die bereits erwähnten Bestimmungen über die Ersatzvornahme der Ernennung der fehlenden Schiedsrichter durch den Vorsitzenden des Verwaltungsrates ${ }^{216}$, sondern auch die dem Prozeßgrundsatz der Offizialmaxime nahekommende Vorschrift des Art. 43, kraft welcher das Schiedsgericht bei Fehlen einer entgegengesetzten Parteienvereinbarung befugt ist, die Parteien zur Vorlage von prozeßrelevanten Beweismitteln aufzufordern und auch Beweisaufnahmen an Ort und Stelle selbst durchzuführen. Weiter kann das Schiedsgericht einstweilige Maßnahmen zur Sicherung der Rechte beider Parteien empfehlen ${ }^{217}$ und auch auf

211 Art. 34 Abs. 2. Vgl. Rule 31-34 der Vergleichsordnung. ICSID/4, S. 67 ff. Das Verfahren wird dadurch geschlossen. Vgl. hingegen Art. 45.

212 Art. 35.

213 Amadio kritisiert diese Bestimmung dahingehend, daß bei Vereinbarung eines dem Schiedsverfahren vorhergehenden obligatorischen Vergleichsverfahren die Parteien nicht in der Lage sind letzteres zu beweisen, da sie dem Schiedsgericht keinerlei Dokumente über das durchgeführte Verfahren vorlegen dürfen. A. a. O., S. 163. Diese Argumentation scheint jedoch zu übersehen, daß die Konvention nur von Berichten und Empfehlungen der Kommission spricht, wodurch z. B. Notifikationen über die Registrierung von Anträgen sicher nicht miteinbegriffen sind. Weiter steht es immer den Parteien offen, eine abweichende Regelung zu vereinbaren.

214 Vgl. dazu die klassische Unterscheidung zwischen Vergleich und Schiedsgerichtsbarkeit von J. B. Moore: "Mediation is recommendatory, arbitration decisive", in "A Digest of International Law ", Bd. 7 (\$ 1069), S. 24.

215 Roulet, a. a. O., S. 147.

216 Siehe oben S. 282.

217 Art. 47. Durchgeführt durch Rule 39 der Schiedsordnung. Dokumentation im Anhang, S. 326. 
Antrag Versäumnisentscheidungen fällen ${ }^{218}$. Doch wird in diesem Falle das Vorbringen der erschienenen Partei nicht als unbestritten angesehen ${ }^{219}$, sondern das Gericht hat vielmehr Sachverhalt und Rechtslage objektiv zu prüfen und kann zu diesem Zweck auch das erwähnte Recht zur unmittelbaren Durchführung von Beweisaufnahmen zu Hilfe nehmen. Eine Entscheidung zu Gunsten der nichterschienenen Partei wäre somit denkbar ${ }^{220}$.

\section{aa. Das anwendbare Recht}

Von zentraler Bedeutung ist die Frage des vom Schiedsgericht anzuwendenden Rechts. Auch hier gibt die Konvention wieder der Parteiautonomie den Vorzug, da das Gericht zunächst die von den Parteien vereinbarten Rechtsvorschriften anzuwenden hat ${ }^{221}$. Diese Bestimmung gestattet den Parteien nicht nur Vereinbarungen, die die Verweisung auf ein bestimmtes nationales Recht oder auf die allgemein anerkannten Rechtsgrundsätze zum Gegenstand haben, sondern begreift auch die autonome Festsetzung von materiellen Rechtsnormen für den bestimmten Streitfall. Betrachtet man die Abneigung ausländischer Investoren gegen eine vorbehaltslose Unterwerfung unter die innerstaatliche Rechtsordnung des Anlagestaates und auf der anderen Seite das traditionelle Mißtrauen der neuen Staaten gegen das außervertragliche Völkerrecht, an dessen Entstehung sie nur zu einem geringen Maße Anteil hatten, so gewinnt gerade letztere Überlegung an Bedeutung, weil dadurch den Parteien die Ermächtigung zur Schaffung einer den Richter bindenden Rechtsgrundlage gegeben ist ${ }^{222}$. Mit anderen Worten: jene Rechtsnormen, unter die ein gegebener Sachverhalt zur Gänze oder zum Teil zu subsumieren ist, werden dem Richter durch die Parteien a p r i o r i vorgeschrieben. Einige Beispiele mögen dieses Konzept näher beleuchten. So wäre es denkbar, daß neben der Unterwerfungsvereinbarung in einem Konzessionsvertrag detaillierte generelle Rechtsvorschriften z. B. in Hinblick auf Auslegung von Verträgen, aufgenommen werden, die dadurch unabhängig von der Tatsache, ob sie dem innerstaatlichen Recht des am Streit beteiligten Staates oder dem Völkerrecht entsprechen, für den Richter als eine lex specialis bindend sind. In gleicher Weise könnten z. B. die Parteien in Hinblick auf den durch die Konvention nicht definierten Begriff der "Investition“ allgemeine Grundsätze festlegen oder auch - und das könnte gerade für Investitionsstreitigkeiten im Rahmen der gegenständlichen Konvention von besonderer Bedeutung zu sein - Kriterien für die Bestimmung der Staatszugehörigkeit von Gesellschaften a b in i t i o bindend für den Richter normieren. Diese bisher wenig beachtete Methode erscheint geeignet, die Unterwerfung von Staaten unter die Jurisdiktion des Zentrums dadurch zu erleichtern, daß sie umstrittene Normen

218 Art. 45 Abs. 2. Vgl. Rule 42 der Schiedsordnung. Dokumentation, S. 326.

$219 \mathrm{Vgl}$. hierzu den Kommentar zu Rule 42: "The must Tribunal now p r o p r i o m o t u examine ... the substantive merit of the 'assertions' made by both parties in order to satisfy itself whether their submissions are well-founded in fact and law. To this end, it may call on the active party for observations, evidence or explanations." ICSID/4, S. 108/09.

220 Id, Note D.

221 Art. 42 Abs. 1.

222 Die Geschichte der internationalen Schiedsgerichtsbarkeit kennt einige Fälle, in welchen die Parteien den Schiedsrichtern detaillerte Anweisungen in Hinblick auf die anzuwendenden Rechtsnormen gaben; als Beispiele seien der Alabama-Fall (,Washingtoner Regeln“), der Orinoco-Dampfschiffahrts-Fall (Anfechtungsgründe von schiedsgerichtlichen Entscheidungen), Stuyt, $\mathrm{Nr}$. 292, die oben erwähnten Fälle der britischamerikanischen Claims Commission 1911 und der mexikanischen Claims Commissions (siehe oben Fußnote 13) und nicht zuletzt Art. 6 der Charter des Internationalen Militärgerichtshofes als Annex des Londoner Abkommens zur Errichtung eines Internationalen Militärgerichtshofes (Tatbestände des "Verbrechens gegen den Frieden“, des "Kriegsverbrechens“ und des "Verbrechens gegen die Menschlichkeit")" vom 8. August 1945. 
durch die Streitparteien selbst klarstellen läßt, damit die richterliche Ermessensfreiheit erheblich einschränkt und somit das aleatorische Moment der rechtlichen Entscheidungsgrundlage zu einem wesentlichen Teil beseitigt.

Bestimmen die Parteien nicht über das anzuwendende Recht, dann kommt innerstaatliches Recht des Anlagestaates einschließlich seines internationalen Privatrechtes sowie Völkerrecht zur Anwendung, wobei der Begriff Völkerrecht von den Schöpfern der Konvention in dem durch Art. 38 des Statuts des IG gegebenen Sinne verstanden wird ${ }^{223}$.

Somit trägt die Konvention der Komplexität der Rechtsverhältnisse zwischen Staaten und ausländischen Investoren dahingehend Rechnung, als sie alle in Betracht kommenden Rechtsgrundlagen der Entscheidung abstrakt formuliert; dabei wird dem innerstaatlichen Recht des Anlagestaates primäre Bedeutung zugemessen ${ }^{224}$, doch durch die ausdrückliche Verpflichtung zur Heranziehung auch der Kollisionsnormen dieses Staates ist eine Verweisung auf das innerstaatliche Recht des Heimatstaates des am Streit beteiligten Individuums durchaus denkbar, wodurch auch diese Rechtsordnung als Entscheidungsbasis fungieren könnte. Gegen diese "automatische Anwendung“. innerstaatlichen Rechts durch eine internatio$\mathrm{n}$ a $\mathrm{l}$ e Rechtssprechungsinstanz wurde u. a. eingewendet ${ }^{225}$, daß das Ermittlungsverfahren zur Kenntnisnahme innerstaatlichen Rechts durch den internationalen Richter von Schwierigkeiten technischer Art begleitet sein würde und weiter, daß der Staat "Herr seiner Rechtsordnung" sei und diese gegebenenfalls jederzeit auch abändern könnte. Dem ersten Einwand kann entgegengehalten werden, daß in der Praxis internationale Gerichte trotz Fehlen ähnlicher Rechtsanwendungsbestimmungen sehr häufig innerstaatliches Recht zur Entscheidung von Vorfragen, wie z. B. der Bestimmung der Staatsangehörigkeit physischer und juristischer Personen $^{226}$ herangezogen hatten; eine ausdrückliche Anwendung innerstaatlichen Rechts sah z. B. der Schiedsvergleich im Fall Trail Smelter ${ }^{227}$ zwischen Kanada und den Vereinigten Staaten vor; ebenso stellt Art. 38 Abs. 1 lit. c des Statuts des IG durch die subsidiäre Anwendbarkeit der „allgemeinen Rechtsgrundsätze“ eine Ermächtigung des internationalen Richters zur rechtsanalogen Heranziehung innerstaatlicher, übereinstimmender Grundsätze dar ${ }^{228}$. Somit ist die Verpflichtung des Schiedsrichters zur Anwendung innerstaatlichen Rechts nach Art. 42 Abs. 1 der Konvention der Ausdruck jahrzehntelanger Praxis internationaler Rechtssprechungsinstanzen ${ }^{229}$ und die damit verbundenen technischen Probleme der Ermittlung dieses Rechts erscheinen durchaus nicht unlösbar.

Auf der anderen Seite kann dem Argument der einseitigen Abänderbarkeit der innerstaatlichen Rechtsnormen durch den Anlagestaat entgegengehalten werden, daß, falls dadurch ein völkerrechtlicher Unrechtstatbestand begründet wird, dann die Normen des Völkerrechts auf diesen Anwendung finden, wie es der letzte Teil des Abs. 1 von Art. 42 ausdrücklich vorsieht. Durch diese Formulierung wird die Funktion des Völkerrechts klar zum Ausdruck gebracht: innerstaatliche Rechts-

223 \& 40 des Berichts.

224 Vgl. dazu Abs. 3 der Präambel: „daß solche Streitfälle zwar für gewöhnlich Gegenstand innerstaatlicher Verfahren sind ....

225 So von Amadio, a. a. O., S. $185 \mathrm{ff}$.

226 Dazu Ralston, Law and Procedure of International Tribunals (1929), S. $51 \mathrm{f}$.

227 AJIL (1938), S. 785; 3 U. N. R. I. A. A., S. 1907 ff.; Art. 4 des Schiedsvergleiches vom 15. April 1935: "The tribunal shall apply the law and practice followed in dealing with cognate questions in the United States of America as well as International Law and Practice "Stuyt, Nr. 403.

228 Über die Praxis des StIG und des IGH siehe Jenks, a. a. O., S. $266 \mathrm{ff}$. Allgemein Verosta, Die allgemeinen Rechtsgrundsätze. Zur Wiederherstellung der klassischen Rechtsquellentheorie, in Osterr. Juristen-Zeitung 5 (1950), S. $101 \mathrm{ff}$.

229 Allgemein dazu siehe J. A. Stoll, L'application et l'interprétation du droit interne par les jurisdictions internationales, Brüssel 1962. 
normen sollten zwar primäre Anwendung finden, solange nicht dadurch eine völkerrechtliche Norm verletzt wird. Tritt dieser Fall ein, dann wird Völkerrecht operativ, so daß man hier von einer Kontrollfunktion des Völkerrechts sprechen kann ${ }^{230}$.

Art. 42 stellt somit gewissermaßen eine Kompromißlösung zwischen jenen beiden Rechtsstandpunkten dar, die für die kapitalexportierenden Staaten auf der einen und die Entwicklungsländer auf der anderen Seite charakteristisch sind: während erstere die „Internationalisierung “ des Rechtsverhältnisses durch Zuordnung desselben in die völkerrechtliche Rechtsordnung vertreten, unterliegt nach Ansicht einer Reihe von Entwicklungsländern das Rechtsverhältnis mit dem ausländischen Investor ausschließlich der eigenen nationalen Rechtsordnung ${ }^{231}$. Dieser Auffassung wurde in Art. 42 durch die primäre Anwendbarkeit innerstaatlichen Rechts zu einem Teil Rechnung getragen, wiewohl auch den Interessen der ausländischen Investoren durch die Anwendbarkeit von Völkerrecht entsprochen wurde ${ }^{232}$. Die Zweckmäßigkeit der Heranziehung von beiden Rechtsordnungen wurde durch die Praxis bestätigt ${ }^{233}$.

Während die nach Art. 42 Abs. 1 erster Satz vereinbarten Rechtsvorschriften die Ermessensfreiheit des Richters in weitestgehendem Maße einschränken können, steht es bei Fehlen einer solchen Vereinbarung dem Richter offen, die geeignete Norm, unter die der gegebene Sachverhalt zu subsumieren ist, frei zu wählen, wobei er lediglich an die Anwendungsvorschrift des zweiten Satzes des gegenständlichen Artikels gebunden ist, d. h. daß innerstaatliches Recht des Anlagestaates einschließlich seines internationalen Privatrechtes sowie Völkerrecht herangezogen werden muß. Aber auch diese Beschränkung fällt, wenn die Parteien eine Entscheidung e $x$ a e q u o e $t$ b o n o vereinbaren ${ }^{234}$ und damit dem Richter eine weitestgehende Ermessensfreiheit einräumen, wie es tatsächlich in der Praxis häufig der Fall ist ${ }^{235}$. Durch eine solche Billigkeitsklausel kann der Richter aus einer beliebigen Rechtsordung die ihm geeignet erscheinende Norm wählen, oder überhaupt die Grenzen des positiven Rechts verlassen, dessen strikte Anwendung im konkreten Fall eine Ungerechtigkeit darstellen würde.

Für diese der Konvention zu Grunde liegenden drei Ermessensbereiche des Richters gilt schließlich weiter, daß unter keinen Umständen das Gericht eine Entscheidung mit der Begründung ablehnen kann, das Recht schweige zu dem streitigen Punkt oder sei unklar ${ }^{236}$.

230 Obwohl von einem anderen Aspekt ausgehend, kommt auch Amadio zu diesem Ergebnis und spricht hier von einer "tutelle du droit internationale ${ }^{\star}$, a. a. O., S. 199.

$231 \mathrm{Vgl}$. hierzu die Ansicht des Rechtsberaters der indonesischen Regierung, Mr. Robert H. Delson, in: "Economic Development and International Law ${ }^{\circ}$, Report of the 2nd Inter-American Conference for Democracy and Freedom, S. 180, 1961: "There are some writers who ... argue that ... the principle p a c t a $s$ u t $s$ e r vanda under international law may be extended to contractual arrangements between states and aliens, provided that such contracts contain a socalled 'internationalizing clause,' i. e. a provision that they are to be governed, wholly or in part, by public international law, or by the general principles of law recognized by civilized nations.

This argument also has no legal justification, since international law can be created only by states, either by general usage involving a number of states, or by treaty between two or more states. A c o n t r a c t be twe en a state and an alien derives its binding force f r m m n i c i a $\mathrm{law}$, and the sanctions of international law cannot be applicable thereto even if the parties desire to make it so ..." (Sperrung von uns). Zitiert bei Hyde, Economic Development Agreements, Rec. des Cours (1962), Bd. 1, S. 293.

232 Dazu siehe A. Broches, The Convention on the Settlement of Investment Disputes between States and Nationals of Other States: Applicable Law and Default Procedure. In: International Arbitration, Liber Amicorum for Martin Domke, The Hague 1967, S. $12 \mathrm{ff}$.

$233 \mathrm{Vgl}$. Art. 45 des Vertrages $\mathrm{z}$ wischen Island und Alusuisse. Siehe Dokumentation, S. 330.

234 Art. 42 Abs. 3.

235 Vgl. Art. 18 des Vertages zwischen Mauretanien und der Société Planet Oil and Mineral Corporation, Dokumentation, S. 329; ebenso Art. 50 des Vertrages zwischen Maurtanien und der Société des mines de Mauritanie (S. O. M. I. M. A.), Dokumentation, S. 329.

236 Art. 42 Abs. 2. 


\section{Der Schiedsspruch}

Nach Abschluß des Erkenntnisverfahrens, das in einen schriftlichen und einen mündlichen Teil zerfällt ${ }^{237}$, muß innerhalb von 60 Tagen der Schiedsspruch von den Mitgliedern des Schiedsgerichtes unterzeichnet sein ${ }^{238}$. Dieser wird mit Stimmenmehrheit aller Mitglieder des Schiedsgerichts gefällt ${ }^{239}$ und bedarf in formeller Hinsicht der Schriftlichkeit und, wie erwähnt, der Unterzeichnung durch die Mitglieder; er hat in materieller Hinsicht eine Begründung zu enthalten und muß alle dem Gericht vorgelegten Fragen behandeln ${ }^{240}$. Ist in letzterer Hinsicht die Entscheidung mangelhaft, so kann das Gericht auf Antrag einer Partei nach Benachrichtigung der anderen Partei über jene Frage entscheiden, die es in dem Schiedsspruch zu behandeln unterlassen hat ${ }^{241}$. Diese Entscheidung gilt sodann als integrierender Bestandteil des Schiedsspruches. Jeder Schiedsrichter kann dem Schiedsspruch seine Individualmeinung beifügen ${ }^{242}$. Eine Veröffentlichung des Spruches erfolgt nur mit Zustimmung der Parteien ${ }^{243}$.

Als Rechtsmittel kennt die Konvention die Auslegung des Schiedsspruches (interpretation), die Wiederaufnahme (revision) und die Aufhebung (annulment) des Schiedsspruches.

Die Auslegung als Rechtsmittel im weiteren Sinne ist bei Meinungsverschiedenheiten der Parteien über „Sinn und Tragweite“244 des Schiedsspruches vorgesehen und wird durch schriftlichen, an den Generalsekretär gerichteten Antrag eingebracht. Über diesen Antrag entscheidet das Gericht, welches den angefochtenen Schiedsspruch erlassen hat. Ist dies nicht möglich, dann wird ein neues Gericht gebildet ${ }^{245}$.

Die Wiederaufnahme als echtes Rechtsmittel sieht die Konvention vor bei Hervorkommen neuer Tatsachen, die geeignet sind, den Schiedsspruch entscheidend zu beeinflussen und die dem Gericht und der antragstellenden Partei vor dem Zeitpunkt der Erlassung des Schiedsspruches unbekannt waren, sofern die Unkenntnis der antragstellenden Partei nicht auf Fahrlässigkeit beruhte246. Der Antrag muß innerhalb von 90 Tagen nach Bekanntwerden der Tatsachen beim Generalsekretär schriftlich eingebracht werden. Als absolute Verjährungsfrist gelten drei Jahre nach Erlaß des Spruches ${ }^{247}$. Über den Wiederaufnahmeantrag entscheidet „nach Möglichkeit" das Gericht, das den Spruch erlassen hat ${ }^{248}$, anderenfalls wird ein neues Gericht gebildet.

Von Bedeutung ist das Rechtsmittel der Aufhebung, das den Ansatz eines internationalen Instanzenzuges dadurch darstellt, daß im Gegensatz zur Interpretation und der Wiederaufnahme notwendigerweise eine vom ursprünglichen Gericht verschiedene Instanz über den Aufhebungsantrag entscheidet. Dieser Antrag muß innerhalb von 120 Tagen nach Erlaß des Schiedsspruches schriftlich an den Generalsekretär gestellt werden ${ }^{249}$ und auf einen der in Art. 52 Abs. 1 enumerativ

\footnotetext{
237 Rule 28 der Schiedsordnung. Siehe Dokumentation, S. 324.

$238 \mathrm{Vgl}$. Rule 46 der Schiedsordnung. Dokumentation, S. 327

239 Art. 48 Abs. 1.

240 Art. 48 Abs. 3. Fehlt eine Begründung, dann liegt ein Aufhebungsgrund nach Art. 52 Abs. 1 vor.

241 Art. 49 Abs. 2 .

242 Art. 48 Abs. 4. Vgl. dazu auch Art. 57 des Statuts des IGH.

243 Art. 48 Abs. 5 .

244 "meaning and scope"; siehe Art. 50 Abs. 1

245 Art. 50 Abs. 2.

246 Art. 51 Abs. 1.

247 Art. 51 Abs. 2

248 Art. 51 Abs. 3.

249 Art. 52 Abs. 2.
} 
aufgezählten Gründe gestützt sein ${ }^{250}$. Über den Antrag entscheidet ein vom Generalsekretär unverzüglich ernannter, aus drei Mitgliedern bestehender Ad-hocAusschuß251. Wird der angefochtene Schiedsspruch aufgehoben, so ist die Streitigkeit einem neu zusammengesetzten Schiedsgericht auf Antrag der Parteien zu unterbreiten ${ }^{252}$.

Wiederaufnahme- und Aufhebungsanträge haben vorläufige aufschiebende Wirkung, sofern solches beantragt wird ${ }^{253}$, während Interpretationsanträgen nur dann aufschiebende Wirkung zukommt, wenn das Gericht eine solche dem Antrag ausdrücklich zuerkennt ${ }^{254}$.

\section{cc. Die Vollstreckung}

Von den genannten Rechtsmitteln abgesehen ist der Schiedsspruch für die Parteien bindend und unterliegt keiner weiteren Überprüfung255. Dieser Grundsatz gilt naturgemäß auch für Entscheidungen über Auslegung, Wiederaufnahme und Aufhebung ${ }^{256}$.

In Hinblick auf seine Rechtsnatur ist der Schiedsspruch trotz der verschiedenartigen Parteienqualität eine e c h t e internationale Entscheidung, da nicht nur das Streitverfahren von völkerrechtlichen Normen, die dem Individuum in prozessualer Hinsicht eine dem Staat gleichgestellte Position einräumen, getragen wird, sondern da auch die Vollstreckung der ergangenen Schiedssprüche durch ein der internationalen Schiedsgerichtsbarkeit bisher unbekanntes Verfahren völkerrechtlich gewährleistet ist: in diesem Sinne betrachtet zwar die Konvention die Rechtswirkungen des Schiedsspruches als in te $\mathrm{r}$ pares bestehend, verleiht aber diesem dahingehend eine Art Fernwirkung, als die Konvention alle Vertragsstaaten verpflichtet, den Schiedsspruch als bindend anzuerkennen und im Bereich ihrer Hoheitsgebiete für die Vollstreckung der darin auferlegten finanziellen Verpflichtungen zu sorgen, wobei dem Schiedsspruch gleicher Rechtscharakter wie einer endgültigen Entscheidung eines innerstaatlichen Gerichtes zukommt ${ }^{257}$. Den Verschiedenheiten der innerstaatlichen Gerichtsorganisation zwischen Einheits- und Bundesstaaten wird dabei insoweit Rechnung getragen, als letztere für die Vollstreckung des Schiedsspruches durch Bundesgerichte sorgen können. In einem solchen Fall muß der Schiedsspruch wie ein endgültiges Urteil der Gerichte eines Gliedstaates behandelt werden ${ }^{258}$.

Es fällt auf, daß in diesem Zusammenhang die Konvention eine Unterscheidung zwischen auf Geld lautende und sonstige Schiedssprüche macht, wobei wohl beide

\footnotetext{
250 Nämlich

a) Nicht ordnungsgemäße Bildung des Gerichts,

a) Nicht ordnungsgemäße Bildung des Gerichts,

c) Bestechung eines Mitglieds des Gerichts,

c) Bestechung eines Abwerwiegende Abweichung von einer grundlegenden Verfahrensvorschrift, und

e) Fehlen der Begründung des Schiedsspruches.

251 Art. 52 Abs. 3.

252 Art. 52 Abs. 6.

253 Obwohl die Konvention von einer solchen automatischen aufschiebenden Wirkung nur im Falle der Aufhebung spricht (Art. 52 Abs. 5), wird diese durch die Schiedsordnung auch auf Wiederaufnahmeanträge ausgedehnt. Rule 54 Abs. 2, siehe Dokumentation, S. 328.

254 Art. 50 Abs. 2.

255 Art. 53 Abs. 1. Während der Ratifikationsdebatte im amerikanischen Senat am 26. März 1966 wurde die Frage aufgeworfen, ob durch Parteienvereinbarung eine durch die Konvention nicht vorgesehene Rechtsmittelinstanz geschaffen werden könnte; mit Recht wurde diese Frage verneint. Wiewohl die Konvention mittelinstanz onomie großen Raum läßt, ergibt sich aus dem Wortlaut der vorliegenden Bestimmung, daß abweichende Vereinbarungen nicht zulässig sind. U. S. Senate, 89th Congress, 2nd Session, Committee on Foreign Relations. Abgedruckt in: V International Legal Materials 4 (July 1966), S. 661.

256 Art. 53 Abs. 2.

257 Art. 54 Abs. 1, Erster Satz.

258 Art. 54 Abs. 1, Letzter Satz.
} 
für alle Staaten bindend sind, aber nur erstere dem direkten Vollstreckungsverfahren im nachstehenden Sinne unterliegen ${ }^{259}$ :

Der Antrag auf Anerkennung und Vollstreckung des Schiedsspruches wird durch die Partei bei dem zuständigen innerstaatlichen Gericht oder einer anderen von dem Vertragsstaat dafür bestimmten "amtlichen Stelle" (authority) durch Vorlage einer vom Generalsekretär beglaubigten Abschrift des Schiedsspruches eingebracht. Zu diesem $Z_{w}$ eck verpflichtet die Konvention die Mitgliedstaaten zur Notifikation der nach innerstaatlichem Recht zuständigen Gerichte oder anderer Behörden an den Generalsekretär ${ }^{260}$. Die weitere Regelung des Vollstreckungsverfahrens überläßt die Konvention den innerstaatlichen Vorschriften über die Vollstreckung von Urteilen ${ }^{261}$. In diesem Zusammenhang ergibt sich für den Vertragsstaat die Notwendigkeit zur Erlassung von innerstaatlichen Durchführungsbestimmungen, da Art. 54 als solcher wohl kaum unmittelbar anwendbares Recht im innerstaatlichen Sinne darstellt ${ }^{262}$. Weiter stellt sich das Problem der Vereinbarkeit mit den Grundsätzen der staatlichen Souveränität für den Fall, daß gegen den unterlegenen Staat in diesem Staat selbst oder in einem anderen Vertragsstaat Vollstreckung des Schiedsspruches durch die Einzelperson begehrt wird. Hier weicht die Konvention von dem Grundsatz der absoluten Prozeßgleichheit zwischen Staat und Individuum ab: sie gibt dem innerstaatlichen Recht des Vertragsstaates in Hinblick auf dessen Vorschriften über die Immunität dieses oder eines fremden Staates den Vorzug263. Trotz dieser den Bedürfnissen der Entwicklungsländer entgegenkommenden Bestimmung ist dadurch eine Vollstreckung auch gegen den fremden Staat nicht ausgeschlossen. Die Rechtssprechungspraxis einer Reihe von Staaten wie Ägypten ${ }^{264}$, Belgien ${ }^{265}$, Italien ${ }^{266}$, Österreich ${ }^{267}$ und der Schweiz ${ }^{268}$ zeigt deutlich die Tendenz zur Einschränkung der absoluten Souveränität von fremden Staaten durch Einführung des Kriteriums von Handlungen $\mathrm{ju} r$ e ges $\mathrm{t}$ i on is und jure imperii, wobei für erstere der Staat wie eine Privatperson den innerstaatlichen Rechtssprechungsorganen unterworfen ist. In dieser Hinsicht wäre es somit denkbar, daß auf Geldleistung lautende Schiedssprüche auch gegen fremde Staaten in einem Vertragsstaat vollstreckt werden können. Doch darf dabei nicht übersehen werden, daß die Mehrzahl der Vertragsstaaten der Konvention, insbesondere die USA, Großbritannien und Frankreich, noch an dem Grundsatz der absoluten Souveränität festhalten. Das Fehlen einer entsprechenden Bestimmung in der Konvention ist daher bedauerlich.

Zusammenfassend läßt sich sagen, daß die Vorschriften über das Schiedsverfahren und Vollstreckung gegenüber dem traditionellen System der Schiedsgerichtsbarkeit trotz der aufgezeigten Mängel einen Fortschritt bedeuten: zum ersten ist es die die Gesamtheit der Vertragsstaaten bindende Wirkung des Schiedsspruches, welche die

259 So auch Amadio, a. a. O., S. 222

260 Art. 54 Abs. 2. Im Sinne dieser Bestimmung erfolgte eine formelle Mitteilung lediglich durch Schweden, das als zuständige Behörde das Ministerium für Auswärtige Angelegenheiten bekanntgab. Doch ergibt sich aus innerstaatlichen, dem Zentrum informell zur Kenntnis. gebrachren Gesetzgebungsakten, daß für die Vereinigten Staaten die Federal District Courts, für Großbritannien der High Court, mit Ausnahme von Schottland (hier Court of Sessions), Nordirland (hier High Court of Northern Irland) und den Kolonien (hier Supreme Court), für Malawi der High Court und für Jamaika der Supreme Court für den Antrag auf Anerkennung und Vollstreckung.

261 Art. 54 Abs. 3

262 Eine allgemeine Verpflichtung ergibt sich aus Art. 69

263 Art. 55.

264 Z. B. im Falle Federated People's Republic v. Kafr El-Zayat Cotton Co. Ltd., International Law Reports (1952), S. $225 \mathrm{ff}$.

265 Société Monnoyer et Bernard v. France. Annual Digest of ILR 1927/28, Fall Nr. 112, sowie Brasseur \& Associates v. The Republic of Greece, op. cit. 1931/32, Fall Nr. 85.

266 Novaco v. United States Navy, ILR 1957, S. 219.

267 Hoffmann v. Dralle. Entscheidung vom 10. 5. 1950, in: Entscheidungen des Osterreichischen Obersten Gerichtshofs in Zivil- und Justizverwaltungssachen, Bd. 23, Nr. 14.

268 United Arab Republic v. Dame X. Siehe AJIL (1961), S. 167. 
theoretische und praktische Voraussetzung zur Einhaltung der erlassenen Schiedssprüche schafft; zum anderen sichert das Verbot der Überprüfung durch innerstaatliche Organe die Unabänderbarkeit der internationalen Entscheidungen. Jene staatlichen Organe, welche die Vollstreckung der konkreten Entscheidung durchzuführen haben, könnten höchstens eine Verletzung des ordre public geltend machen, doch erscheint auch dies in Hinblick auf den Inhalt der Entscheidung, der sich auf die Zuerkennung von Geldleistungen beschränkt, als wenig wahrscheinlich ${ }^{269}$.

Obzwar, wie erwähnt, der Einzelperson im Vollstreckungsverfahren eine nachteilige Rolle zuerkannt wird, darf doch nicht übersehen werden, daß das Völkerrecht eine Rechtsordnung hauptsächlich zwischen Staaten darstellt, in der das Individuum nur solche Rechte zuerkannt bekommt, die eben diese Staaten bereit sind, auf Kosten ihrer Souveränität abzugeben. Mag auch Art. 55 als Mangel erkannt werden, so darf man doch nicht übersehen, daß die Geschichte der internationalen Schiedsgerichtsbarkeit nur sehr wenige Fälle kennt, in denen die Erfüllung des Schiedsspruches verweigert wurde. Und schließlich enthält die Konvention keine Bestimmung, die dem Heimatstaat des Investors verbieten würde, bei Nichterfüllung des Schiedsspruches sein diplomatisches Schutzrecht in Anspruch zu nehmen und auf zwischenstaatlicher Ebene gegen den anderen Staat vorzugehen, sondern betont vielmehr dieses Recht durch die Bestimmung des Art. 27 Abs. 1.

Im großen und ganzen schafft somit die Konvention geeignete verfahrensmäßige Voraussetzungen für die Verbesserung des internationalen Investitionsklimas, was durch die verhältnismäßig große Zahl der Staaten, die bisher die Konvention ratifiziert haben, bestätigt wurde. Auf diese Tatsache soll abschließend ein Blick geworfen werden.

\section{Die Konvention und die neuen Staaten in Übersee}

Bis zum gegenwärtigen Zeitpunkt wurde die Konvention von 57 Staaten unterzeichnet, von welchen 38 bereits ratifiziert haben ${ }^{270}$. Die Konvention ist nach Ablauf von 30 Tagen nach Hinterlegung der zwanzigsten Ratifikationsurkunde am 14. Oktober 1966 in Kraft getreten ${ }^{271}$.

Während sämtliche Industriestaaten der westlichen Welt die Konvention unterzeichnet und schon teilweise ratifiziert haben, ist die Reaktion der Entwicklungsländer in Hinblick auf die Neubelebung des Schiedsgerichtsgedankens recht unterschiedlich und reicht von vorbehaltsloser Annahme bis zu kategorischer Ablehnung.

269 So auch Roulet, a. a. O., S. 151.

$270 \mathrm{Das}$ Manuskript wurde mit 30. April 1968 abgeschlossen. Bis zu diesem Zeitpunkt wurde die Konvention von folgenden Staaten ratifiziert (in Klammern der Zeitpunkt des Inkrafttretens): Ceylon (11. Nov. 1967), Dahome (14. Okt. 1966), Elfenbeinküste (14. Okt. 1966), Frankreich (20. Sept. 1967), Gabun (14. Okt. 1966), Ghana (14. Okt. 1966), Island (14. Okt. 1966), Jamaika (14. Okt. 1966), Japan (16. Sept. 1967), Jugoslawien (20. April 1967), Kamerun (2. Feb. 1967), Kenia (2. Feb. 1967), Kongo-Brazzaville (14. Okt. 1966), Korea (23. März 1967), Madagassische Republik (14. Okt. 1966), Malawi (14. Okt. 1966), Malaysia (14. Okt. 1966), Mauretanien (14. Okt. 1966), Marokko (10. Juni 1967), Niederlande (14. Okt. 1966), Niger (14. Dez. 1966), Nigeria (14. Okt. 1966), Norwegen (15. Sept. 1967), Obervolta (14. Okt. 1966), Pakistan (15. Okt. 1966), Senegal (21. Mai 1967), Sierra Leone (14. Okt. 1966), Somalia (30. März 1968), Schweden (28. Jan. 1967), Togo (10. Sept. 1967), Trinidad und Tobago (2. Feb. 1967), Tschad (14. Okt. 1966), Tunesien (14. Okt. 1966), Uganda (14. Okt. 1966), Vereinigtes Königreich von Großbritannien und Nordirland (18. Jan. 1967), Vereinigte Staaten von Amerika (14. Okt. 1966), Zentralafrikanische Republik (14. Okt. 1966), Zypern (25. Dez. 1966). Von nachstehenden Staaten wurde die Konvention unterzeichnet, aber noch nicht ratifiziert: Athiopien (21. Sept. 1965), Afghanistan (30. Sept. 1966), Belgien (15. Dez. 1965), Burundi (17. Feb. 1967), China (13. Jan. 1966), Dänemark (11. Okt. 1965), Bundesrepublik Deutschland (27. Jan. 1966), Finnland (14. Juli 1967), Griechenland (16. März 1966), Indonesien (16. Februar 1968), Irland (30. Aug. 1966), Italien (18. Nov. 1965), Liberia (3. Sept. 1965), Luxemburg (28. Sept. 1965), Nepal (28. Sept. 1965), Osterreich (17. Mai 1966), Schweiz (22. Sept. 1967), Singapur (2. Feb. 1968) und Sudan (15. März 1967). Doc. ICSID/3/Rev. 3.

271 Art. 68 Abs. 2 . 
Eine Erörterung der Haltung der neuen Staaten wird aus Gründen der Systematik zweckmäßig nach geographischen Gesichtspunkten in den afrikanischen, asiatischen und ibero-amerikanischen Bereich gegliedert.

\section{a) Die Haltung der neuen Staaten in Afrika}

In der Welt der neuentstandenen Staaten Afrikas hat die Konvention erstaunlich großen Widerhall gefunden. Zweiundzwanzig Staaten, nämlich Dahome, die Elfenbeinküste, Gabun, Ghana, Kamerun, Kenia, Kongo (Brazzaville), die Madagassische Republik, Malawi, Mauretanien, Marokko, Niger, Nigeria, Obervolta, Senegal, Sierra Leone, Somalia, Togo, Tschad, Tunesien, Uganda und die Zentralafrikanische Republik haben die Konvention ratifiziert, von Äthiopien, Burundi, Liberia und dem Sudan wurde sie unterzeichnet; bisher haben also fast Zweidrittel der neuen Staaten dieses Kontinents ihr wohlwollendes Interesse an einer internationalen Schiedsgerichtsbarkeit zu erkennen gegeben. Nachdem die Konvention keine Registrierungspflicht von Unterwerfungsvereinbarungen vorsieht, ist offiziell die Zahl jener afrikanischen Staaten, die sich der Jurisdiktion des Zentrums unterworfen haben, nicht bekannt, doch ist dem Generalsekretär des Zentrums bereits inoffizielle Information über eine Reihe von Verträgen zugegangen, die eine Unterwerfungsklausel enthalten ${ }^{272}$. Offiziell hat sich Mauretanien bisher als erster afrikanischer Staat in zwei Verträgen ${ }^{273}$ der Jurisdiktion des Zentrums unterworfen. Im Sinne von Art. 13 Abs. 1 wurden von neun afrikanischen Staaten, nämlich von Dahome, Kenia, Mauretanien, Obervolta, Senegal, Togo, Tunesien, Uganda und der Zentralafrikanischen Republik je zwei bis vier Personen zur Aufnahme in die Verzeichnisse der Vermittler und Schiedsrichter dem Generalsekretär notifiziert, wobei nicht nur Staatsangehörige des eigenen Staates vorgeschlagen wurden; Mauretanien und Obervolta machten Persönlichkeiten französischer Staatsangehörigkeit als Vermittler bzw. Schiedsrichter namhaft ${ }^{274}$.

Nicht zuletzt auch diese Tatsache spricht für eine positive Einstellung der genannten Staaten zum Gedanken einer Beilegung von Investitionsstreitigkeiten durch internationale Instanzen und gibt zur Vermutung Anlaß, daß Staaten, die von ihrem Recht zur Namhaftmachung von Schiedsrichtern und Vermittlern Gebrauch gemacht haben, auch bereit sein werden, sich in irgendeiner Form den vergleichsoder schiedsgerichtlichen Institutionen des Zentrums zu unterwerfen.

Für den Bereich der neuentstandenen Staaten Afrikas kann daher festgestellt werden, daß trotz der grundsätzlichen Haltung in Hinblick auf die Integrität ihrer Souveränität ein großer Teil dieser Staaten direkt oder indirekt seine Bereitschaft zur Inanspruchnahme der durch die Konvention geschaffenen Wege zur Beilegung von Investitionsstreitigkeiten ausgedrückt hat.

\section{b) Die Haltung der Staaten Asiens}

Obzwar geringeres, aber immerhin ein noch beachtliches Echo fand die Konvention im Bereich der asiatischen Staatenwelt. Von Japan als kapitalexportierendem Land

272 ICSID, First Annual Report 1966/67, S. 5.

273 Siehe Dokumentation, S. 329.

274 Von Mauretanien wurden die französischen Professoren V. Berger-Vachon, P. Lampue, H. Solus und G. Vedel, von Obervolta der Berater im Ministère du Plan et des Travaux Publics, M. Lecardeur, als Vermittler und Schiedsrichter namhaft gemacht. ICSID, Membership of Panels, February 15, 1968. 
abgesehen, wurde bis zum heutigen Tage die Konvention von vier Entwicklungsländern ratifiziert, nämlich von Ceylon, Korea (Süd), Malaysia und Pakistan und von fünf weiteren Staaten, nämlich von Afghanistan, China (Formosa), Indonesien, Nepal und Singapur unterzeichnet. Eine Ratifikation auch dieser Staaten ist in naher Zukunft zu erwarten.

Von Interesse ist in diesem Zusammenhng die diesbezügliche Gesetzgebung Afghanistans: obzwar dieser Staat die Konvention noch nicht ratifiziert hatte, sieht das Investitionsförderungsgesetz mit Wirkung vom 20. Januar $1967^{275}$ durch Art. 19 Abs. 1 vor, daß von im Gesetz bestimmten Ausnahmen abgesehen, Streitigkeiten zwischen der königlichen Regierung und dem ausländischen Investor über die Anwendung dieses Gesetzes in Úbereinstimmung mit der Weltbankkonvention beigelegt werden sollten, wobei - im Sinne der Konvention - eine zusätzliche Unterwerfungsvereinbarung noch erforderlich sein sollte. Damit wird generell eine bestimmte Art von Streitigkeiten von der Zuständigkeit der innerstaatlichen Rechtssprechungsorgane ausgenommen und einer internationalen Instanz zugewiesen, abhängig jedoch vom künftigen Konsens beider Parteien ${ }^{276}$.

Von dem Recht zur Namhaftmachung von Vermittlern und Schiedsrichtern nach Art. 13 Abs. 1 der Konvention haben bisher nur Korea (Süd) und Pakistan Gebrauch gemacht, welche je acht Personen dem Zentrum zur Aufnahme in die Verzeichnisse notifizierten ${ }^{277}$.

Obwohl z. B. die ölexportierenden Staaten des Nahen Ostens und auch Indien bisher der Vertragsgemeinschaft fernblieben, darf doch diese Haltung nicht als endgültig angesehen werden. Das Beispiel Indonesiens hat gezeigt, daß auch souveränitätsbewußte Staaten, die sich bisher dem Gedanken an eine Drittinstanz zur Entscheidung von Streitigkeiten mit ausländischen Investoren nur widerwillig fügten $^{278}$, im Interesse der Anlockung von Auslandskapital eine geänderte Haltung einnehmen können, zumal die Ratifikation der Konvention noch keine obligatorische Schiedsgerichtsbarkeit begründet, wohl aber die spätere Unterwerfung unter eine Drittinstanz erleichtert.

\section{c) Die Haltung der lateinamerikanischen Staaten}

Dem Anliegen und den Zielen dieser Zeitschrift entsprechend ${ }^{279}$, wäre abschließend auch die Haltung der Staaten im iberoamerikanischen Bereich in die Untersuchung einzubeziehen.

275 Foreign and Domestic Incentive Law, siehe Dokumentation, S. 331.

276 Schiedsklauseln finden sich bereits in einer Reihe von Investitionsförderungsgesetzen, wobei jedoch die vorgesehene Schiedsinstanz nicht zwingend internatonalen bzw. quasi-internationalen Charakter aufweisen muß, sondern auch im Rahmen der innerstaatlichen Rechtsordnung errichtet werden kann. Siehe z. B. Art. XII des griechischen Investitionsförderungsgesetzes vom 5. September 1953 bei Baade, Gesetzgebung zur Förderung ausländischer Kapitalanlagen (1957), S. 55; weiter Section 11 des liberianischen Gesetzes (Investment Incentive Code) vom 21. März 1966. Siehe Dokumentation, S. 331. Section 8 des Ghana Capital Investment Acts 1963 hingegen ist ähnlich wie das genannte afghanische Gesetz ein Beispiel für die Zuständigkeitsübertragung an eine internationale Instanz.

277 ICSID, Membership Panels, February 15, 1968.

278 Vgl. Art. 7 lit. a des Vertrages zwischen P. T. Perusahaan Minjak Nasional (Permina), einer indonesischen staatlichen Gesellschaft und der kanadischen Gesellschaft Asamera Oil Corporation Ltd. vom 1. September 1961: "In the event that there is disagreement of any kind between Permina and Asamera concerning the terms of this Agreement and in the event that agreement cannot be reached between Permina and Asamera, then in that event these disputes shall be submitted to the courts of law in Indo-

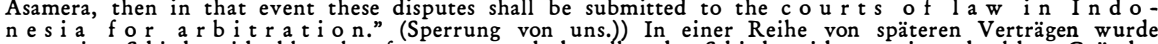
zwar eine Schiedsgerichtsklausel aufgenommen, doch sollte das Schiedsgericht aus irgendwelchen Gründen nicht gebildet werden können, sollten wieder indonesische Gerichte zuständig sein. Vgl. Art. 25 des Vertrages $z$ wischen der staatlichen Gesellschaft P. N. Pertambangan Minjak Nasional (Permina) und P. T. Stanvac Indonesia, einer $\mathrm{zwar}$ als indonesisch registrierten, aber vom Ausland kontrollierten Gesellschaft, vom 25. September 1963. Siehe Platts Oilgramm News Service vom 19. März 1964, S. $1 \mathrm{ff}$.

279 Vgl. den einführenden Beitrag von Prof. Krüger, Verfassung und Recht in Übersee, in dieser Zeitschrift 1 (1968), S. $3 \mathrm{ff}$. 
Die lateinamerikanische Haltung $\mathrm{zu}$ schiedsgerichtlicher Beilegung von Streitigkeiten zwischen Staaten und ausländischen Investoren ist durch jene Auffassung charakterisiert, die in der sogenannten Calvo-Klausel ihren juristischen Niederschlag gefunden hat und noch weiter findet. Im wesentlichen wird darunter die in einem Vertrag zwischen Staat und ausländischer Privatperson aufgenommene Bestimmung verstanden, alle zukünftigen Streitigkeiten der Zuständigkeit der innerstaatlichen Gerichte zu unterwerfen und auf die Inanspruchnahme des diplomatischen Schutzrechtes des Heimatstaates zu verzichten ${ }^{280}$. Abgesehen von der letztgenannten Bestimmung würde das bedeuten, daß unter allen Umständen ausschließlich innerstaatliche Gerichte zur Streitbeilegung herangezogen werden können, welche hauptsächlich innerstaatliches Recht zur Anwendung bringen. Die Errichtung einer internationalen Instanz, welche auch nach anderen Grundsätzen entscheiden könnte, soll durch die genannte Klausel ausgeschlossen werden. Durch innerstaatliche Gesetzgebung wurde diese schiedsgerichtsfeindliche Haltung bestätigt: so enthielt das panamaische Investitionsförderungsgesetz vom 10. Mai 1950 die Bestimmung ${ }^{281}$, daß, „sofern das Unternehmen mit ausländischem Kapital arbeitet“, es „jeden Streitfall der Entscheidung des nationalen Gerichtshofes unterwerfen und für sich auf jede diplomatische Intervention verzichten“ muß. Die venezolanische Verfassung vom 26. Januar $1961^{282}$ präsumiert auch bei Nichtvorhandensein der Calvo-Klausel in Verträgen, die öffentliche Interessen berühren, eine solche als integrierender Bestandteil des betreffenden Vertrages und schließt dadurch jedwede Möglichkeit einer schiedsgerichtlichen Beilegung von Streitigkeiten aus dem Vertrage aus.

Es erscheint daher keineswegs verwunderlich, daß sich die lateinamerikanischen Gouverneure der Weltbank auf der Jahresversammlung in Tokio ${ }^{283}$ im Jahre 1964 geschlossen gegen das Projekt der Schaffung einer internationalen Instanz zur Beilegung von Investitionsstreitigkeiten aussprachen; eine Haltung, die unter dem Schlagwort „El No de Tokyo“ in die Entstehungsgeschichte der Konvention eingegangen ist ${ }^{284}$.

Dazu darf bemerkt werden, daß die bloße Ratifikation noch keine Verpflichtung zur Unterwerfung unter eine Schiedsinstanz erzeugt. Verbietet die innerstaatliche Rechtsordnung den schiedsgerichtlichen Weg, so steht es immer noch den Parteien frei, sich nur den gegebenen Vergleichseinrichtungen zu unterwerfen, die gewiß noch unter den Begriff des „freundschaftlichen Weges“ des Art. 127 der venezolanischen Verfassung fallen, wodurch einem Konflikt mit dem nationalen Recht ausgewichen werden könnte 285 .

Obwohl bisher noch kein iberoamerikanischer Staat die Konvention unterzeichnet hat, kann deshalb noch nicht auf eine generelle abweisende Haltung zur Konvention auch für die Zukunft geschlossen werden. Vielleicht erscheint dem einen

\footnotetext{
280 Gerade letztere Bestimmung wurde in einer Reihe von Entscheidungen internationaler Schiedsgeridhte als rechtlich unwirksam erachtet, da die Einzelperson auf ein dem Staat zustehendes Recht nicht verzichten kann. Darüber siehe Donald R. Shea, The Calvo Clause. A Problem of Inter-American and International Law \& Diplomacy, University of Minnesota Press (1955).

281 Art. 2 j. Siehe Baade, a. a. O., S. 79.

282 Art. 127. "In contracts of public interest, if it not be contrary to law according to the nature of same, there shall be considered incorporated, even though it were not i n c l u ded the rei n, a clause to the effect that doubts and controversies which may arise on said contracts and which should not be resolved in an amicable manner by the contracting parties shall be decided by the competent courts of the Republic, in conformance with its law, and such, for no reason or cause, may give rise to foreign claims." (Sperrung von uns.) Venezuela Constitution, herausgegeben von W. Poulses, Publisher of Venezuelan Laws in English, Caracas, Venezuela.

283 Siehe oben S. 274.

284 Ansprache des (damaligen) Rechtsberaters der Weltbank, Mr. A. Broches, vor der American Bar Association am 27. Mai 1965 in San Juan, Puerto Rico, S. 6. 285 Id, S. 7.
} 
oder anderen lateinamerikanischen Staat die Annahme der durch die Konvention gebotenen Möglichkeiten der Beilegung von Streitigkeiten im Interesse der Beseitigung eines schwebenden Streitfalles oder - und das mag unter Umständen zutreffend sein - zur Anziehung ausländischen Kapitals in Zukunft als opportun. Somit könnten der rechtlichen Tradition entstammende Gründe den wirtschaftlichen Bedürfnissen weichen und eine Lockerung der Haltung auch im lateinamerikanischen Bereich bringen.

\section{Zusammenfassung}

In Anbetracht des Inkrafttretens der Weltbank-Konvention vor knapp zwei Jahren mag es vielleicht verfrüht sein, eine abschließende Wertung der geschaffenen Vergleichs- und schiedsgerichtlichen Institutionen vorzunehmen, zumal bisher noch kein Antrag auf Einleitung eines Verfahrens gestellt wurde. Doch die verhältnismäßig große Zahl der neuen Staaten in Afrika und Asien, die im Grunde mit der Beilegung von Investitionsstreitigkeiten auf internationalem Wege einverstanden sind, bietet Beweis dafür, daß die juristische Gestaltung der Konvention den Bedürfnissen eines großen Teiles der Entwicklungsländer entspricht. Gerade die Mechanik des strengen Konsensprinzips ${ }^{286}$ schafft den geeigneten Ausgleich zwischen den Erfordernissen der Souveränität und den Interessen des ausländischen Investors.

Die entscheidende Neuerung im Bereich der Methoden zur Beilegung internationaler Streitigkeiten ist jedoch die Schaffung eines direkten Zugangsrechtes für Einzelpersonen $\mathrm{zu}$ internationalen Instanzen auf institutioneller Grundlage und die daraus resultierende größtmöglichste Verwirklichung der prozessualen Gleichstellung $\mathrm{zwischen} \mathrm{Individuum} \mathrm{und} \mathrm{Staat.} \mathrm{Darin} \mathrm{ist} \mathrm{auch} \mathrm{der} \mathrm{Fortschritt} \mathrm{gegenüber}$ dem OECD-Projekt zu erblicken ${ }^{287}$, welches zwar ebenfalls eine schiedsgerichtliche Beilegung von Investitionsstreitigkeiten vorsieht, doch der Einzelperson nur dann Zugang zu dem Schiedsgericht gewährt, wenn der Heimatstaat auf die Geltendmachung des Anspruches verzichtet und der Anlagestaat sich der Schiedsgerichtsbarkeit unterworfen hat ${ }^{288}$. Darüber hinaus kann der Heimatstaat auch in diesem Falle selbst ein Verfahren einleiten mit der Wirkung, daß das begonnene Verfahren seines Staatsangehörigen suspendiert wird ${ }^{289}$. Durch das Fehlen eines Interventionsverbotes, wie es die Weltbank-Konvention vorsieht ${ }^{290}$, läuft damit jede Investitionsstreitigkeit Gefahr, zu einem politischen und internationalen Streitfall auszuarten. Das OECD-Projekt unterscheidet sich in dieser Hinsicht daher kaum vom traditionellen System der Schiedsgerichtsbarkeit, dessen Mängel in Kapitel I aufgezeigt wurden.

Auf der anderen Seite enthält der OECD-Entwurf materielle Bestimmungen zum Schutze des Eigentums des ausländischen Investors ${ }^{291}$. Das Fehlen analoger Bestimmungen in der Weltbank-Konvention und deren Beschränkung auf verfahrensrechtlichen Normen könnte vielleicht als Mangel betrachtet werden. Es darf jedoch nicht übersehen werden, daß in jeder Rechtsordnung Verfahrensnormen und materielle Normen in gleicher Weise Bedeutung haben, und daß somit das Vor-

286 Siehe oben S. $281 \mathrm{ff}$.

287 Draft Convention on the Protection of Foreign Property, Paris 1967.

288 Art. 7.

289 Art. 7 lit. d.

290 Siehe oben S. 283.

291 So Art. 3. 
handensein eines geeigneten Verfahrens schon einen großen Schritt zur Verwirklichung des Rechts bedeutet. In welchem Ausmaße sich Staaten und ausländische Investoren der durch die Konvention geschaffenen Möglichkeiten bedienen werden, wird die Zukunft weisen. 